\title{
Predicting post-traumatic growth inventory (PTGI) based on the perceived social support; the mediating role of resilience in women with breast cancer: A structural equation modeling approach
}

\begin{abstract}
Background and Objective: Experience of life-threatening illnesses such as cancer leads to the comprehension of its positive outcomes along with its negative consequences. This study aimed to predict the post-traumatic growth inventory based on perceived social support mediated by resilience in women with breast cancer using a structural equation approach.

Materials and Methods: This correlational study with a descriptive-analytic design was conducted using the Multidimensional Scale of Perceived Social Support (MSPSS), the Connor-Davidson Resilience Scale (CD-RISC), and the Post-traumatic Growth Inventory. Two hundred women with breast cancer were enrolled using convenience sampling. The participants had visited Imam Hossein Hospital in Tehran ( $n=62$ ) and Imam Ali Complex of the Alborz University of Medical Sciences ( $n=138) 6$ months after their surgery from April to September 2019.

Results: Social support had a significant effect on resilience $(P<0.05)$. In addition, resilience had a significant effect on post-traumatic growth $(P<0.05)$. Results showed the significant indirect effect of social support on post-traumatic growth through resilience $(P<0.05)$. The coefficient of determination indicated that social support alone explained $15.2 \%$ of the variance observed in resilience. The coefficient of determination was 56.3 for post-traumatic growth. Therefore, resilience and social support together explained $56.3 \%$ of the variance in post-traumatic growth where resilience had a greater contribution compared to social support (a larger beta coefficient).

Conclusion: Based on the results of the study, perceived social support affects post-traumatic growth with the mediating role of resilience in patients with breast cancer. Therefore, strengthening social support and resilience can play an effective role in post-traumatic growth.

Keywords: Breast Cancer, Perceived Social Support, Post-Traumatic Growth Inventory, Resilience.

Paper Type: Research Article.
\end{abstract}

Citation (Vancouver): Babazadeh Namini S, Elahi A, Seirafi M, Sabet M, Azadeh P. Predicting post-traumatic growth inventory (PTGI) based on the perceived social support; the mediating role of resilience in women with breast cancer: A structural equation modeling approach. Iran J Health Educ Health Promot. Summer 2021;9(2): 172-186.

- Citation (APA): Babazadeh Namini S., Elahi A., Seirafi M., Sabet M., Azadeh P. (Summer 2021). Predicting post-traumatic growth inventory (PTGI) based on the perceived social support; the mediating role of resilience in women with breast cancer: A structural equation modeling approach. Iranian Journal of Health Education \& Health Promotion., 9(2),172-186.
Sima Babazadeh Namini PhD Candidate, Dept. of Psychology, Islamic Azad University of Dubai, UAE

Seyed Ahmad Elahi

* Assistant Professor, Dept. of Surgery, Alborz University of Medical Sciences, Karaj, Iran. (Corresponding Author) a.elahi@abzums.ac.ir

Mohammad Reza Seirafi Assistant Professor, Dept. of Psychology, Islamic Azad University, Karaj, Iran

Mehrdad Sabet

Assistant Professor, Dept. of Psychology, Islamic Azad University Roudehen, Iran

Payam Azadeh

Associate Professor Dept. of Radiotherapy \& Oncology, Shahid Beheshti University of Medical Sciences, Tehran, Iran.

Received: 2020/11/23

Accepted: 2021/03/18

Doi: 10.52547/ijhehp.9.2.172 


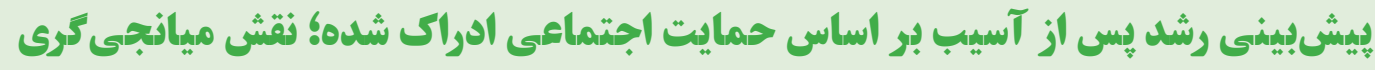 تاب آورى در زنان مبتلا به سرطان يُستان: رويكرد مدل يابى معادلات ساختارى اسي}

سيما باباز اده نمينى دانشجوى دكترى تخصصى، گروه روانشناسى، دانشكاه

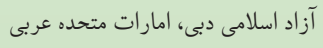

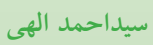

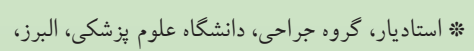
a.elahi@abzums.ac.ir

ايران. (نويسنده مسئول)

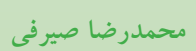
استاديار، كروه روانشانياسى، دانشكاء آزاد اسلامى،

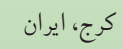
مهرداد ثابت ايت كران استاديار، كروه رواديَ روانشناسى، دانشكاء آزاد اسلامى

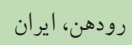
بيام آزاده دانشيار، كروه راديوترابى و آنكولوزى دانشكاء علوم يز شكى شهيد بهشتى، تهران، ايران

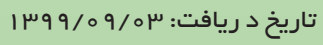
تاريخ يذيرش:

\section{-}

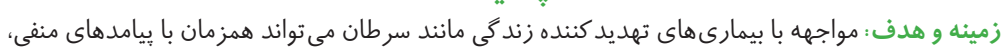

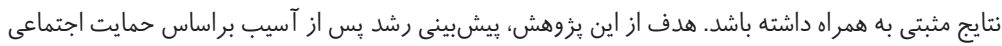

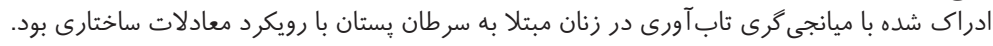

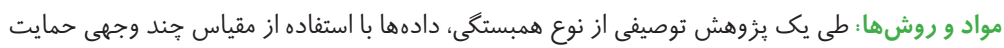

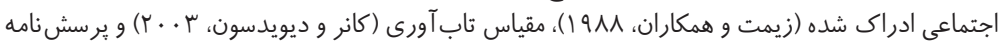

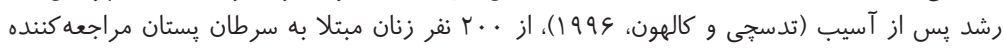

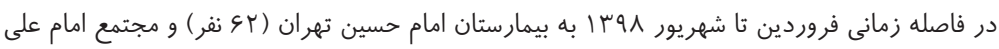

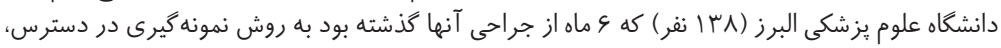

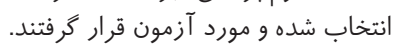

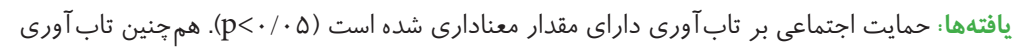

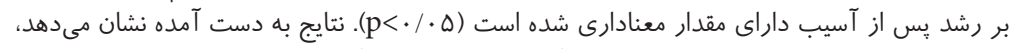

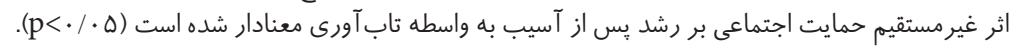

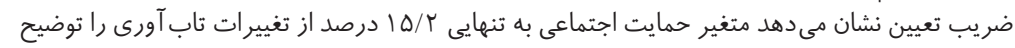

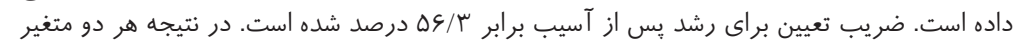

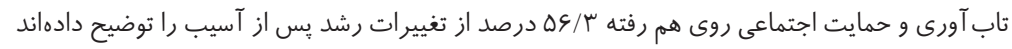

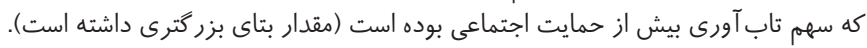

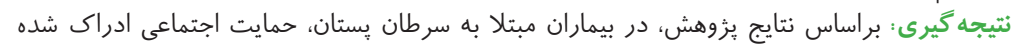

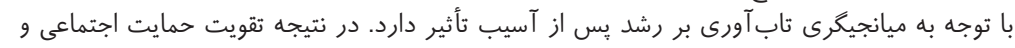

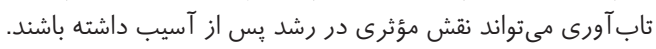

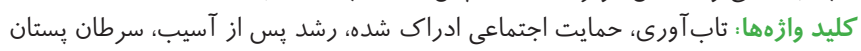
نوع مقاله : مطالعه يزوهشى. تاب اورى حمان.

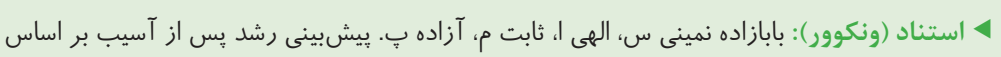

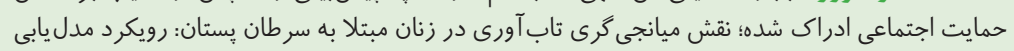

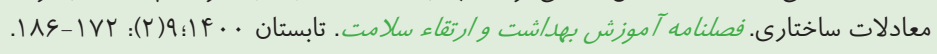

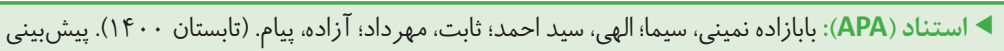

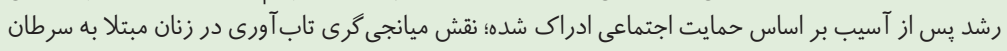

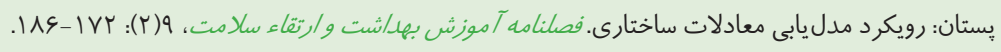


كه با برقرارى ارتباط شروع مىشود و با تداوم آن، به ايجاد ارتباطى همدلانه و در نهايت به يك شبكه ايمنى براى بيمار مى انجامد. تحقيقات إندات نشان داده است كه حمايت اجتماعى نقش عمدهاى در تطابق و كنار

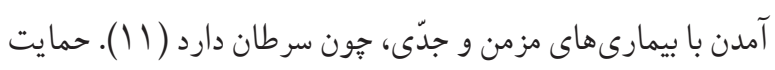
اجتماعى باعث مىشود فرد احساس كند كه مورد علاقه است، از وى مر اقبت مىشود، ارزش و احترام دارد و متعلق به يك شبكه از از

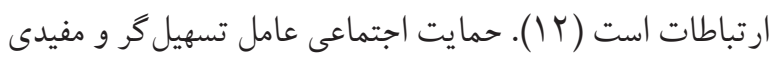

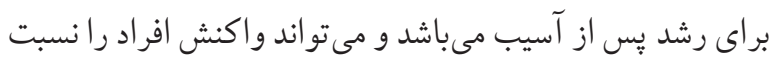

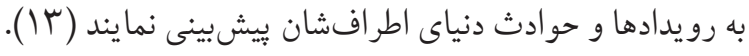

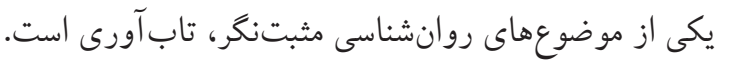
تاب آورى با توانايى ساز كارى مثبت در مصيبتها و و آسيبهاى

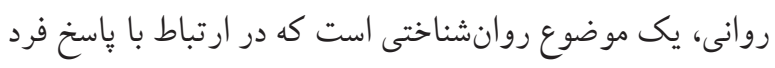

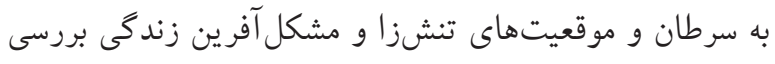

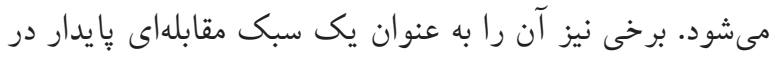

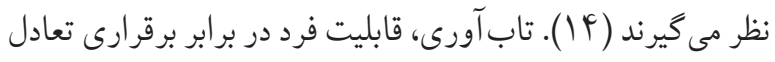
زيستى، روانى و معنوى در مقابل شرايط مخاطرهآميز است (1) (1) ).

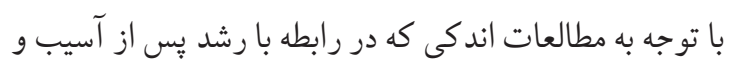

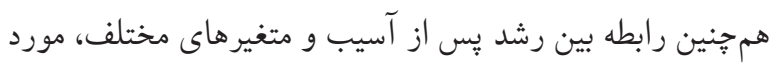

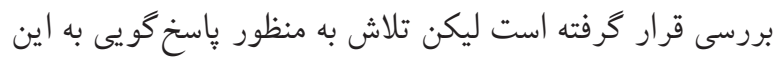

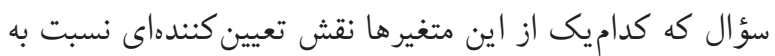

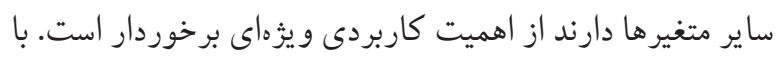
توجه به شيوع بالاى سرطان بستان و اهميت انطباق فرد با بيمارى

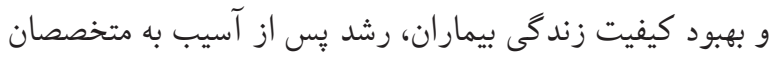
حوزه سلامت در اين خصوص كمك شايان توجهى مىنمايد.

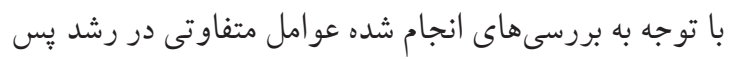

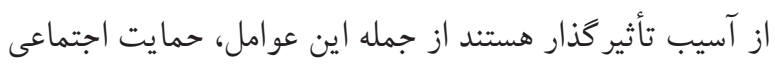

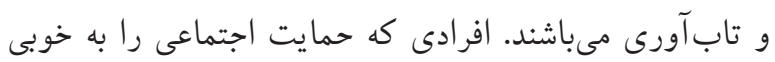

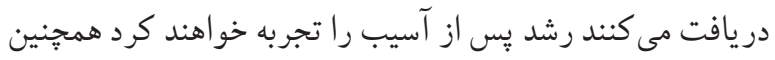

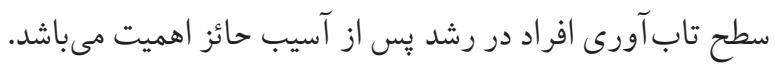

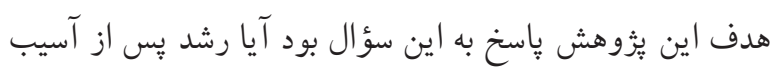

شيوع فزايندة بيمارىهاى مزمن' به جالش قرن حاضر در بخش

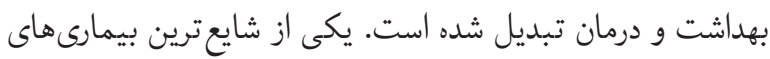

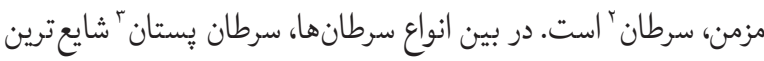
سرطان در ميان زنان در سراسر جهان مىباشد ( (1). تشخيص اوليه و درمان، منجر به افزايش طول عمر بيماران مبتلا به سرطان بستان

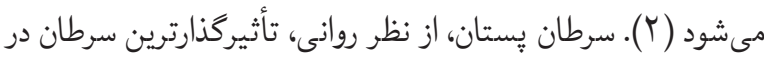

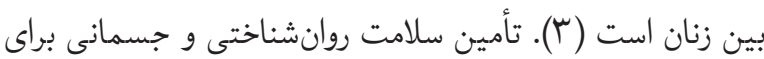

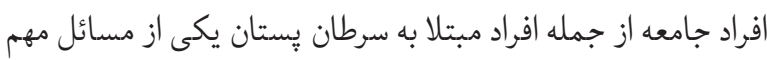

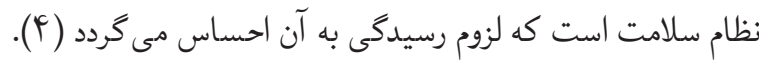
تشخيص و درمان سرطان اكرجه مىتواند بسيار يرتنش و و تجربهاي آسيبزا باشد و اثرات روانى مخربى داشته باشد، اما تحقيقات كسترده نشان داده است كه تجربه سرطان هم جنين مى تواند محركى

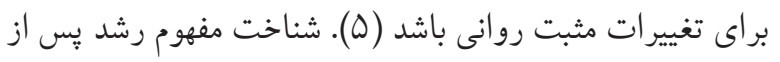

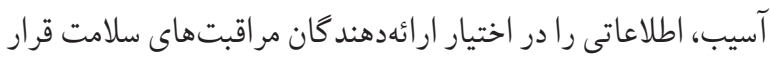

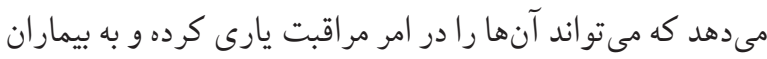

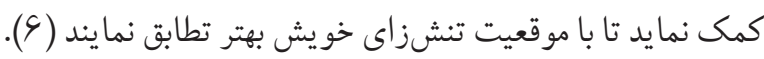

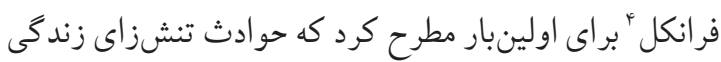

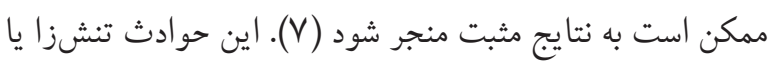
آسيبزننده ممكن است به عنوان عامل تسهيل كننده براى تغييرات

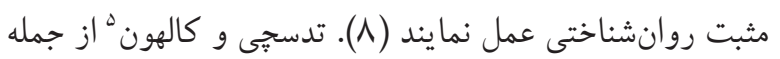

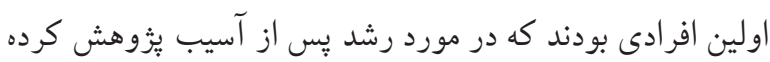

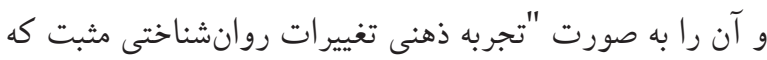

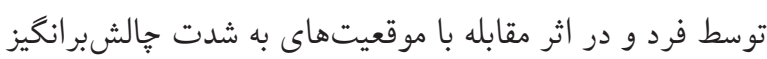

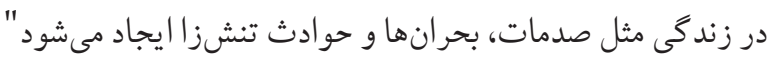
تع يف كردند (9). حمايت اجتماعى از جنبههاي مهم مراقبت مدرن از سرطان است

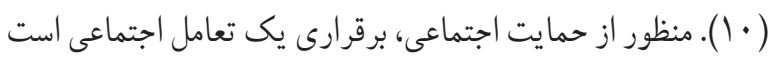

1. Chronic Illness

2. Cancer

3. Breast Cancer

4. Frankle

5. Tedeschi \& Calhoun 
براساس حمايت اجتماعى ادراك شده با ميانجى گرى تاب آورى در اجتماعى ادراك شده؛ متغير بيشبين و رشد بِ از آسيب، متغير

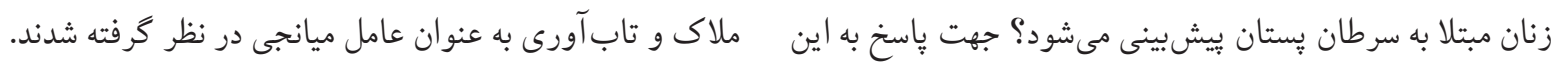

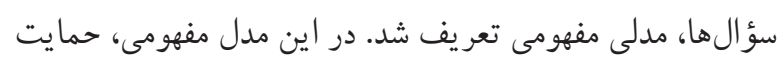

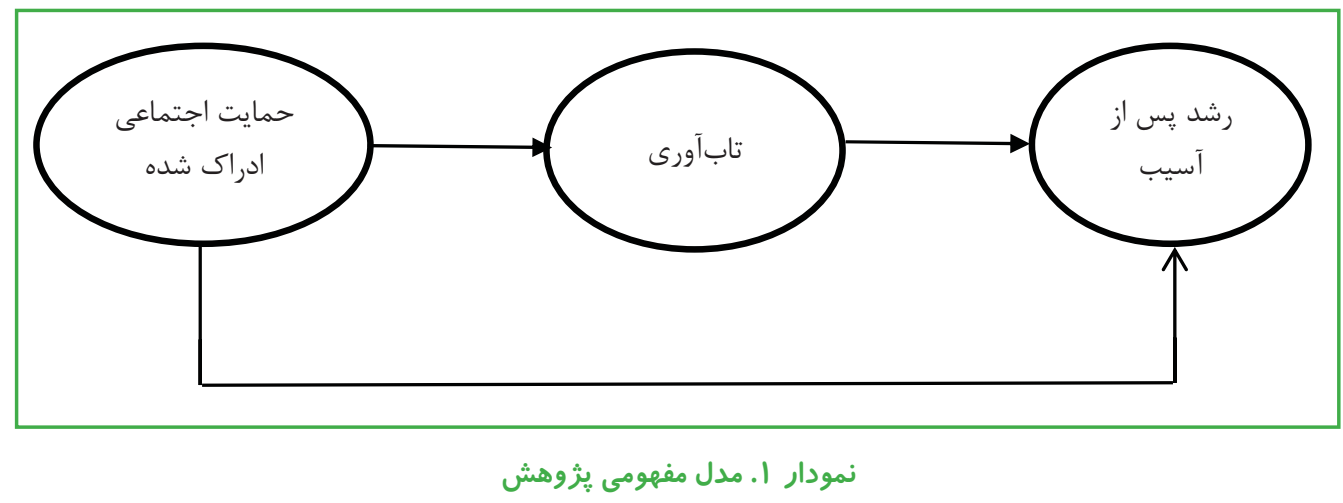

روش برورسى

به منظور بررسى رشد يس از آسيب، از يرسشنامه تدسجى

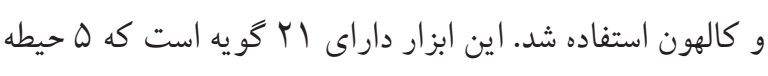

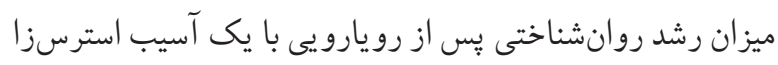

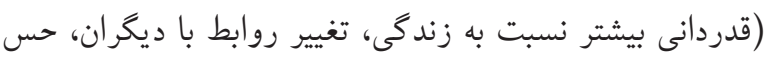

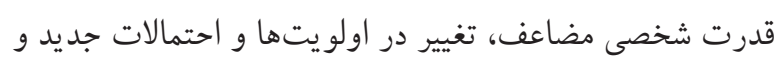

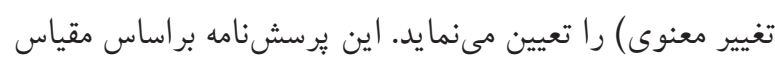

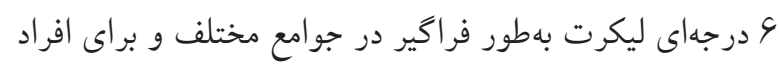

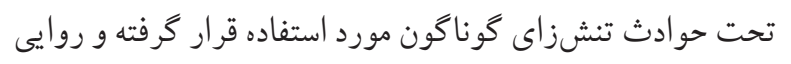
و وِايايى آن توسط تدسجى و كالهون تأييد شده است.

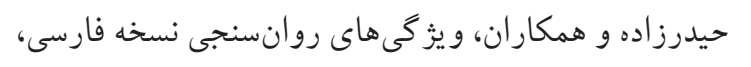

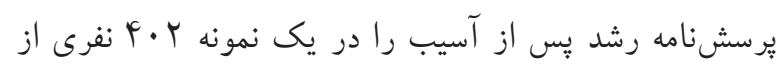

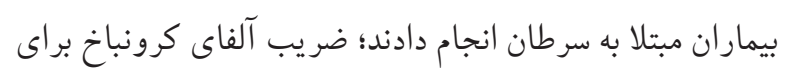

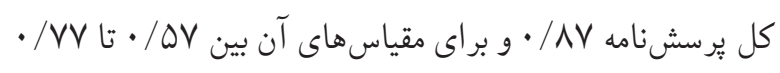

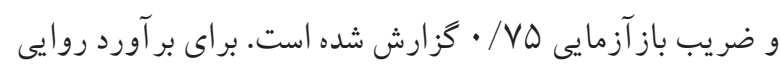

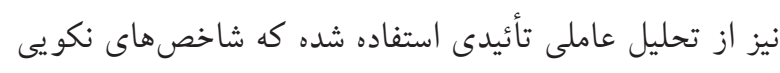

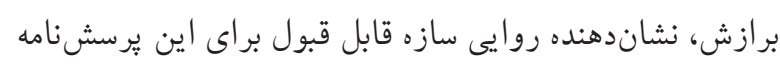

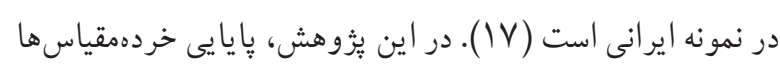

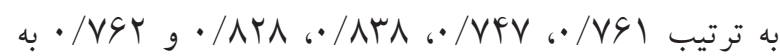
دست آمد. روش يُوهش حاضر توصيفى و از نوع همبستخى است. از نظر هدف، برونى

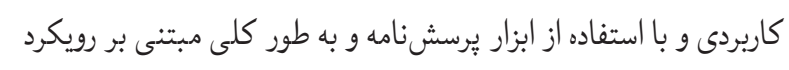

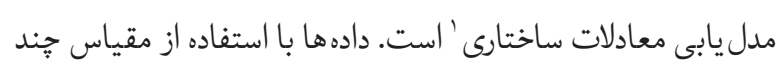

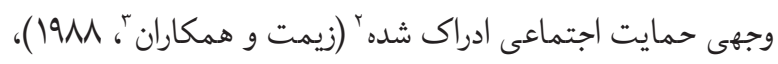

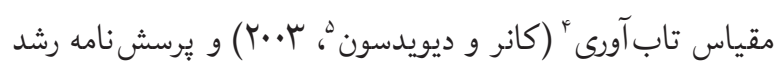

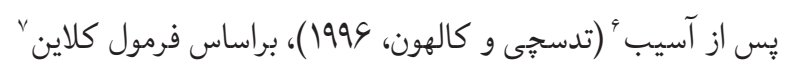
(انتخاب حجم نمونه براساس اصول مدليابى معادلات ساختارى

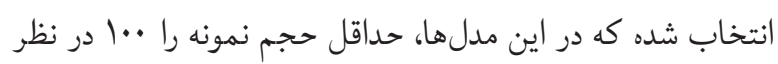

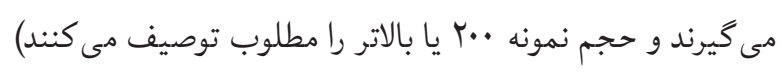

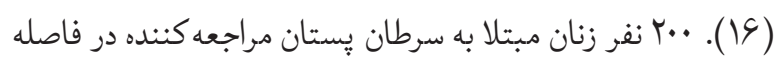

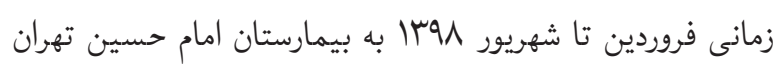

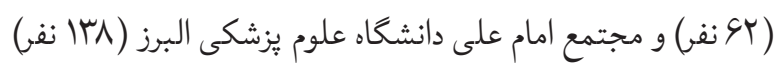

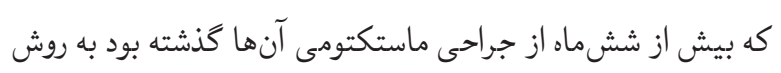
نمونه كيرى در دسترس، انتخاب شده و پِس از آكاه شدن از اهداف يُزوهش، مورد آزمون قرار كرفتند.

1. Structural Equation Modeling (SEM)

2. Multidimensional Scale of Perceived Social Support

3. Zimet et al

4. Resilience Scale

5. Conner \& Davidson

6. Post-Traumatic Growth Inventory Questionnaire (PTGI)

7. Kline Formula 


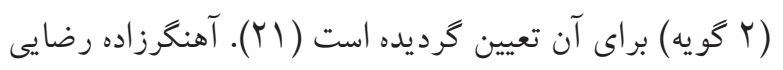

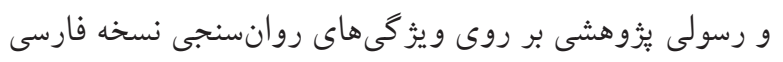

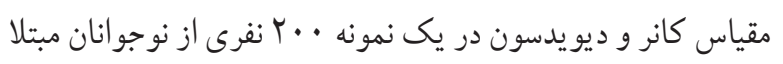

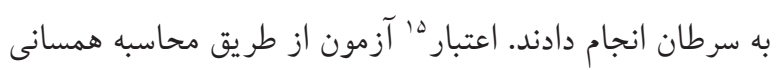

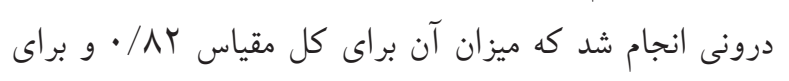

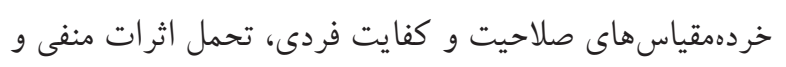

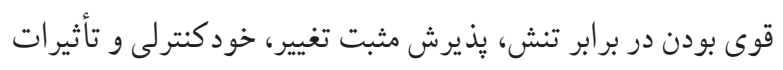

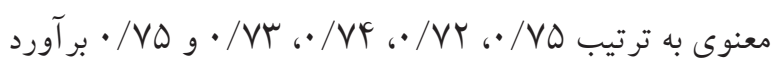

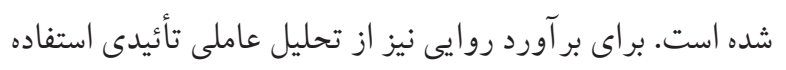

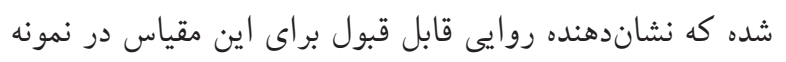

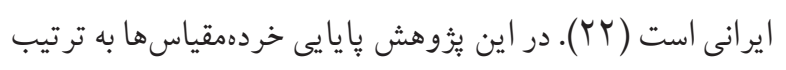

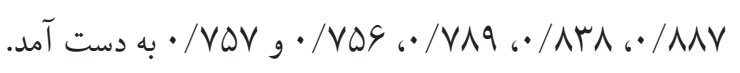

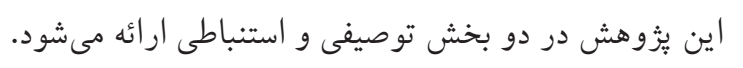

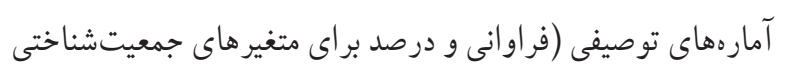
شامل (نوع درمان، سابقه بيمارى در خانواده، سن، تأهل، تعداد

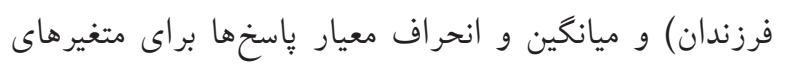

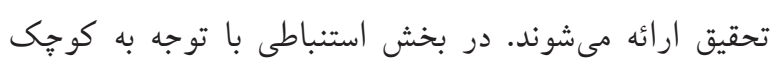

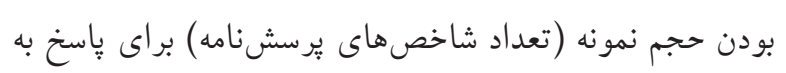

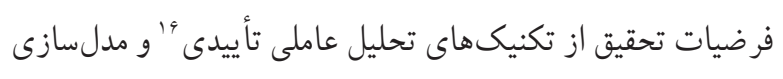

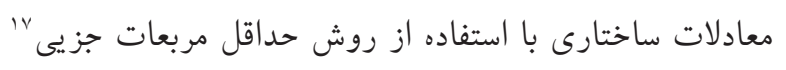

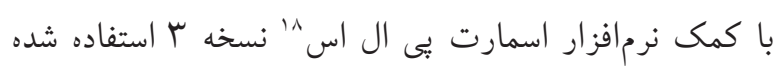

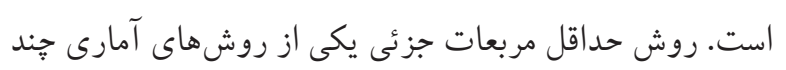

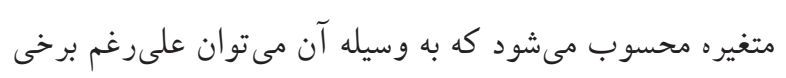

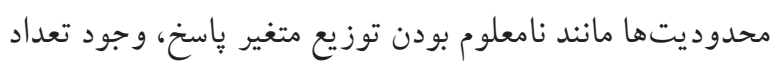

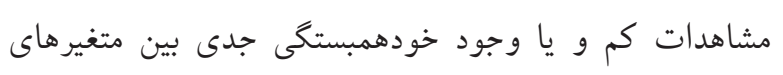

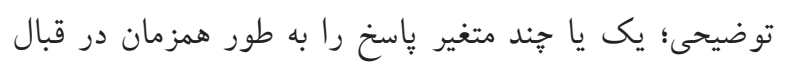

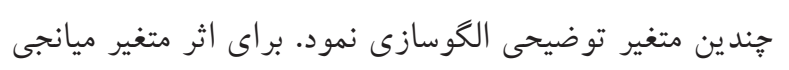
نيز از روش آزمون سوبل ج' استفاده شده است.

15. Reliability

16. Confirmatory factor analysis (CFA)

17. Partial Least Square (PLS)

18. SMARTPLS

19. Sobel Test

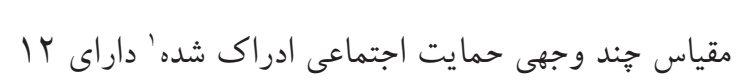

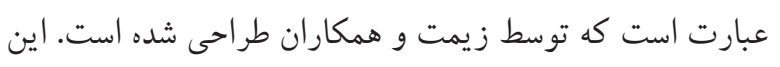

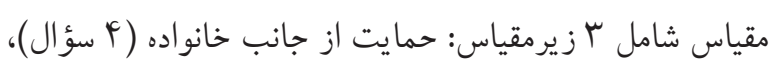

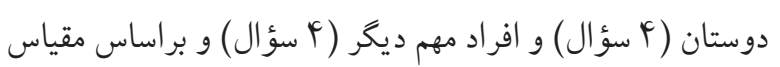

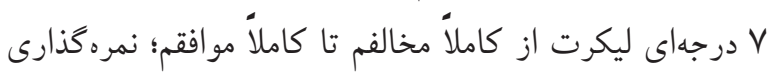

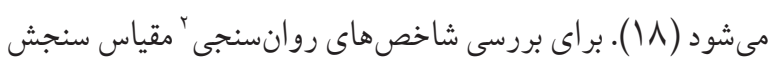

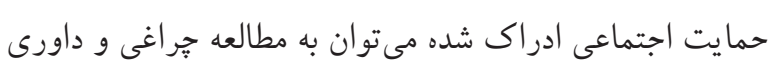

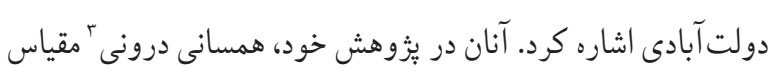

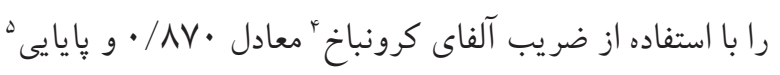

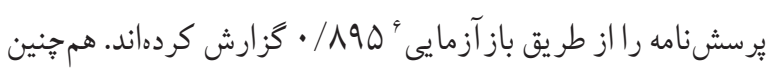

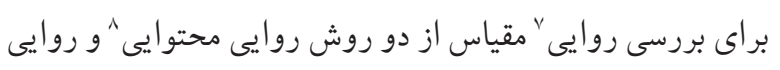

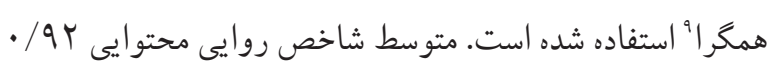

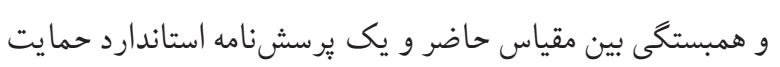

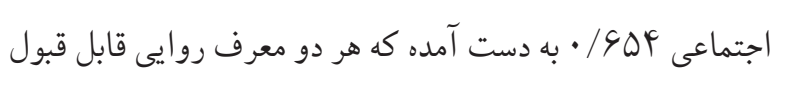

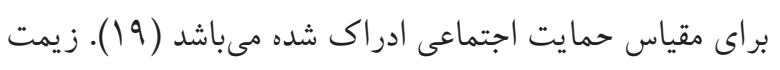

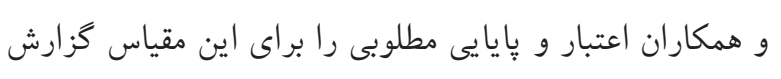

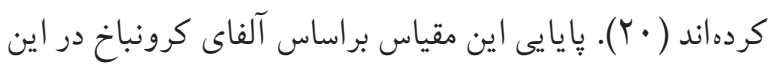

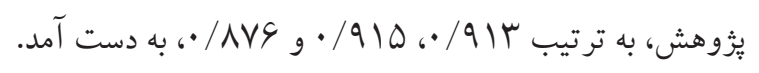

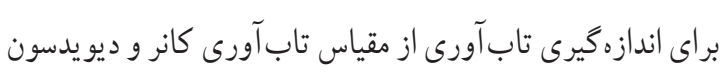

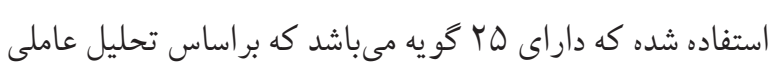

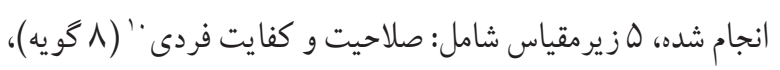

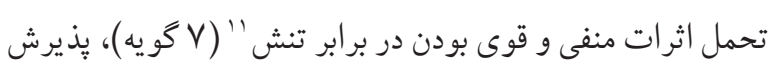

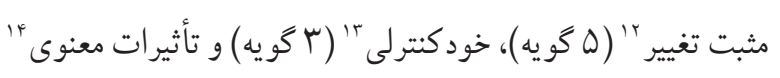

1. Scale of Perceived Social Support

2. Psychometric Properties

3. Internal Consistency

4. Cronbach's Coefficient Alpha

5. Stability

6. Test-Retest

7. Validity

8. Contact Validity

9. Convergent Validity

10. Personal Competence

11. Tolerance of Negative Effect and Strengthening Effects to Stress

12. Positive Acceptance of Change

13. Self- Control

14. Spiritual Influences 
شيمىدرمانى يا جراحى و راديوترايى) و (T/\% تجربه تنها يك مورد

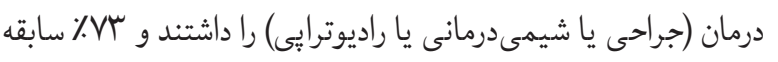

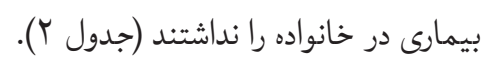

\section{جدول ץ. نتايج توصيفى متغير هاى كيفى جمعيتشناختى}

\begin{tabular}{|c|c|c|c|}
\hline درصد & فراوانى & كروه & متغير \\
\hline
\end{tabular}

\begin{tabular}{|c|c|c|c|}
\hline 1. & rq & صفر & \multirow{4}{*}{ عداد فرزندان } \\
\hline io & 1.9 & $r-1$ & \\
\hline rr & iv & $r-r$ & \\
\hline I & 10 & بيشتر از F & \\
\hline 4 & Ir & مجرد & \\
\hline
\end{tabular}

\begin{tabular}{|c|c|c|}
\hline$\Lambda \mu / \Delta$ & ISV & متأهل \\
\hline$\mu / \mu$ & rl & مطلقه \\
\hline
\end{tabular}

\begin{tabular}{|c|c|c|c|}
\hline$\Delta F$ & $\vee \wedge$ & پِايينتر از دييلم & \multirow{4}{*}{ تحصيلات } \\
\hline re & iA & دييلم & \\
\hline rV & $\Delta F$ & ليسانس & \\
\hline 1. & $r$. & وق ليسانس و بالاتر & \\
\hline
\end{tabular}

\begin{tabular}{|c|c|c|c|}
\hline$r / \Delta$ & $\checkmark$ & هيج كدام & \multirow{7}{*}{ نوع درمان } \\
\hline $1 r / \Delta$ & rv & جراحى & \\
\hline $9 / 0$ & ir & شيمى درمانى & \\
\hline 1 & r & راديوترايى & \\
\hline $1 \cdot 10$ & rl & جراحى - شيمىدرمانى & \\
\hline$\Delta / \Delta$ & 11 & جر احى - راديوتر إيى & \\
\hline$\Delta 9 / \Delta$ & 119 & جراحى - راديوترايى - & \\
\hline$r V$ & $\Delta F$ & بلى بلى & \multirow{2}{*}{ سابقه بيمارى در } \\
\hline$v^{\mu}$ & lis & خير & \\
\hline
\end{tabular}

متوسط سن افراد اYT/KN سال بوده است. متوسط سن ابتلابه بيمارى در افراد نمونه ب/ T سال بوده است، متوسط مدت زمان

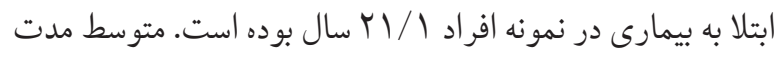

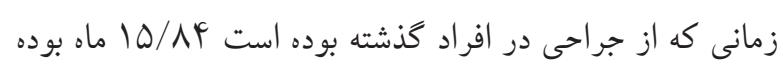

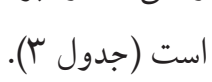

يكى ديكر از مفروضات معادلات ساختارى، عدم وجود همخطى شديد بين شاخصهاى مدل مى باشد. براى بررسى همخطى ميان

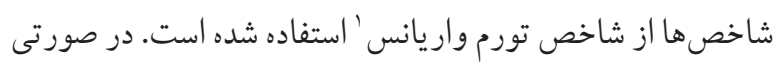

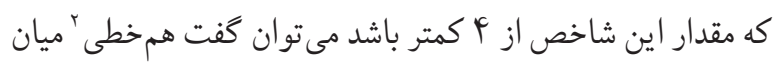

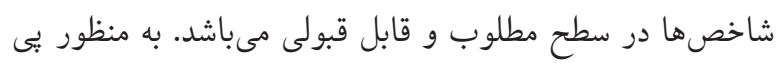

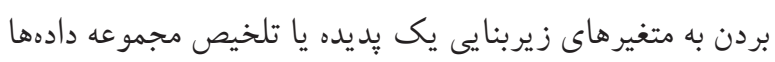

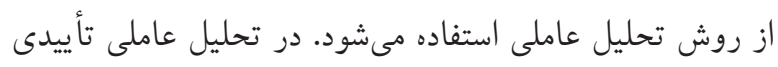
يّش فرض اساسى آن است كه هر عاملى با زيرمجموعه خاصى از

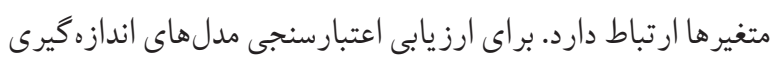
از روايى و پِايايى استفاده شده است (جدول ()).

\begin{tabular}{|c|c|}
\hline حد مجاز & شاخص \\
\hline آلفاى كرونباخ و پِايايى تركيبى بالاتر از V/ • & 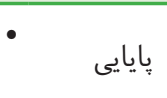 \\
\hline
\end{tabular}

جدول ا. شرايط برقرارى يايايى و روايى همخرا

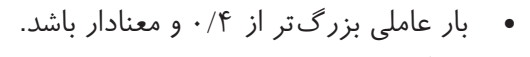

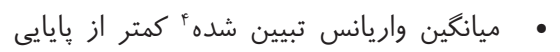

$$
\text { تر كيبى باشد. }
$$

روايى همخرا ميانكين واريانس تبيين شده بزركتر از ه/.

$$
\begin{aligned}
& \text { باشد. }
\end{aligned}
$$

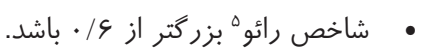

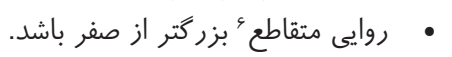

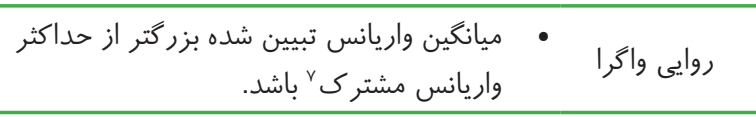

از مجموع •·Y نفرى كه در اين تحقيق مشاركت داشتهاند، •9٪ داراى

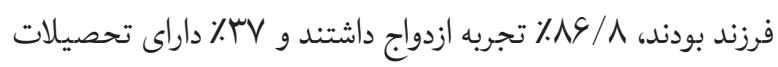

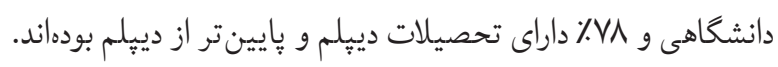

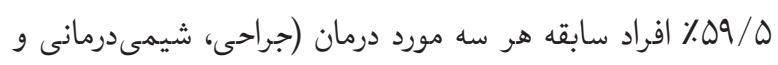

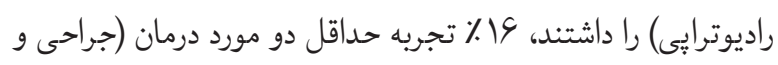

1. Variance Inflation Factor (VIF)

2. Multicolinearity

3. Composite Reliability (CR)

4. Average Variance Extracted (AVE)

5. Rho-A

6. Cv-Com

7. Maximum Shared Squared Variance (MSV) 
شده است و نشان از تأييد روايى همكرا در مدل مىباشد. از ديكر

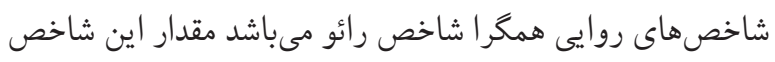
نيز براى تمامى متغيرهاى تحقيق بالاتر از 9 / • بوده است و ونشان از همداز

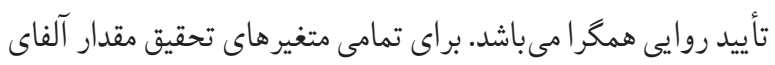

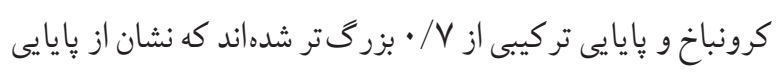

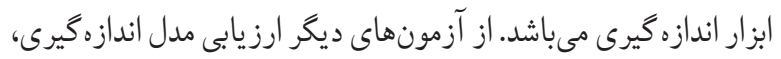

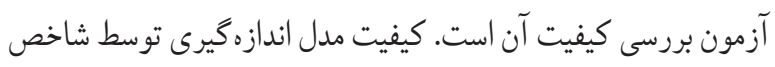

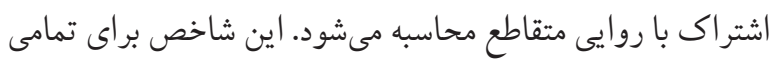

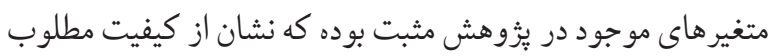
و بالاى مدلاندازهيرى مى دهد. براى بررسى هم خطى ميان شاخصها

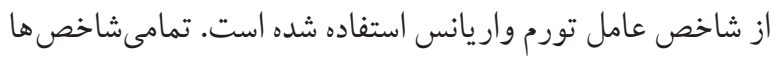

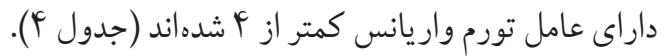

جدول سّ. نتايج توصيفى متغير هاى كمى جمعيتشناختى

\begin{tabular}{|c|c|c|c|c|}
\hline بيشترين & كمترين & انحراف & ميانگين & متغير هاى جمعيتشناختى \\
\hline $9 \Lambda$ & ro & $1 . / . r$ & $r \wedge / \mu l$ & سن (سال) \\
\hline s૬ & . & $\mid F / \varepsilon r$ & F & سن ابتلا به بيمارى \\
\hline $1 \wedge$. & . & $r \Delta / \Delta V$ & $r y / 1$ & مدت زمان ابتلا به بيمارى (سال) \\
\hline 11. & . & $r \cdot|r|$ & $10 / \Lambda F$ & مدت زمان پٍ از جراحى (ماه) \\
\hline
\end{tabular}

بر طبق نتايج به دست آمده تمامى شاخصها داراى بار عاملى

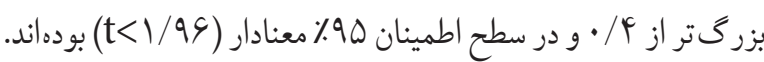
يكى از شاخصهاى بررسى روايى همخر ا شاخص ميانكين واريانس

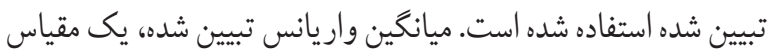
از همكرايى در ميان مجموعهاى از گويههاى مشاهده شده يك ساختار

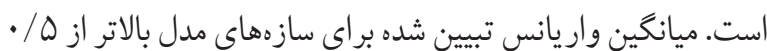

جدول Fا. شاخصروايى همگَرا، هايايى و توصيفى

\begin{tabular}{|c|c|c|c|c|c|c|c|c|c|c|c|c|c|}
\hline \multicolumn{2}{|c|}{ آمار توصيفى } & \multicolumn{9}{|c|}{ تحليل عاملى تأييدى } & \multirow[b]{2}{*}{ شاخص } & \multirow{2}{*}{ زير (متغير هاى } & \multirow[b]{2}{*}{ مقياس } \\
\hline معيار & ميانگين & متقاطع روايى & تميانگين واريانس & تر پايايى & شاخص & كرونباخ & تورم & معادارى & آماره تى & بارعاملى & & & \\
\hline \multirow{3}{*}{$r / \cdot q$} & \multirow{3}{*}{ V/VI } & \multirow{3}{*}{$\cdot / r 19$} & \multirow{3}{*}{$\cdot / \Delta V Y$} & \multirow{3}{*}{. /Var } & \multirow{3}{*}{$\cdot / \mathrm{VV}$} & \multirow{3}{*}{$\cdot \mid V 41$} & $1 / \cdot V^{f}$ & $\cdot / \cdots 1$ & $\Delta / 9 \vee r$ & $\cdot 10 \cdot 9$ & PTGI_01 & \multirow{3}{*}{ قدردانى بيشتر } & \multirow{20}{*}{ رَد رِ آسب از } \\
\hline & & & & & & & $1 / 494$ &.$/ \cdots 1$ & rV/rVT & ./Ar & PTGI_03 & & \\
\hline & & & & & & & 1/oro & $\cdot / \cdots 1$ & $\varphi g / \mu \mid \Lambda$ & $\cdot / \wedge \vee \wedge$ & PTGI_11 & & \\
\hline \multirow{5}{*}{$r / \wedge r$} & \multirow{5}{*}{$|V / \mu|$} & \multirow{5}{*}{$\cdot / \mu \cdot \Delta$} & \multirow{5}{*}{$\cdot / 4 \cdot r$} & \multirow{5}{*}{$\cdot / \wedge \Lambda \mid$} & \multirow{5}{*}{ - /AFG } & \multirow{5}{*}{$\cdot / \wedge r \wedge$} & ו/rル & $\cdot / \cdots 1$ & $s / V \cdot 1$ & $\cdot / \Delta \Delta F$ & PTGI_02 & \multirow{5}{*}{ احتمالات جديت اولغيت در } & \\
\hline & & & & & & & $r / \cdot \Delta$ & $\cdot / \cdots 1$ & $r q / r \mu r$ & - /Arr & PTGI_13 & & \\
\hline & & & & & & & $r / r r$ & $\cdot / \cdots 1$ & rI/frq & . Ars & PTGI_14 & & \\
\hline & & & & & & & $1 / 994$ &.$/ \cdots 1$ & $r I / \Lambda$ & $\cdot / \vee \wedge \Delta$ & PTGI_19 & & \\
\hline & & & & & & & $r / \mathscr{F} \wedge \Lambda$ & $\cdot / \cdots 1$ & $r \Delta / F V r$ & $\cdot /$ /NOF & PTGI_21 & & \\
\hline \multirow{4}{*}{ r/^q } & \multirow{4}{*}{$\mid F / F F$} & \multirow{4}{*}{$\cdot /$ TVD } & \multirow{4}{*}{$\cdot / \Delta \Delta \Delta$} & \multirow{4}{*}{$\cdot /$ ANr } & \multirow{4}{*}{ - /AFo } & \multirow{4}{*}{ ·/Ar^ } & $1 / \wedge \vee 1$ & $\cdot / \cdots 1$ & $r G / \Lambda \cdot r$ & . MAFF & PTGI_04 & \multirow{4}{*}{ حس قدرت } & \\
\hline & & & & & & & $r / \mathcal{F}$ & $\cdot / \cdots 1$ & FG/GGG & $\cdot / 1 \wedge \Delta$ & PTGI_08 & & \\
\hline & & & & & & & $1 / 414$ & $\cdot / \cdots 1$ & IV/rAs & . NRG & PTGI_10 & & \\
\hline & & & & & & & $1 / 91 r$ &.$/ \cdots 1$ & $r r / \Delta V I$ & $\cdot / V V r$ & PTGI_17 & & \\
\hline \multirow{2}{*}{$\Delta / V V$} & & & & & & & I/rOT & $\cdot / \cdots 1$ & FG/GAr & $\cdot / 1990$ & PTGI_05 & & \\
\hline & r r/Vq & $\cdot / r \cdot r$ & $\cdot / V r$ & ·/ArV & •/VG4 & • VAr & I/ror &.$/ \cdots 1$ & $19 / 1 \cdot V$ &.$/ \vee 99$ & PTGI_16 & تغيير & \\
\hline & & & & & & & I/VTS & $\cdot / \cdots 1$ & $1 \cdot /$ rrf & $\cdot / 9 F \Delta$ & PTGI_06 & & \\
\hline & & & & & & & 1/994 & $\cdot / \cdots 1$ & $r \cdot / \wedge r$ & $\cdot /$ VAF & PTGI_07 & & \\
\hline$\varepsilon / .0$ & $r q / r y$ & . &.$\angle \Delta c$ & . Jurr &.$/ Y Y$ &.$/ y^{e} Y$ & $1 / r \cdot 9$ & $\cdot / \cdots 1$ & G/DQF & $\cdot / 0 \cdot 1$ & PTGI_12 & تغيير روابط با & \\
\hline & & & & & & & $1 / \Delta \Delta F$ &.$/ \cdots 1$ & $|V / \cdot| F$ & $\cdot / V F \wedge$ & PTGI_15 & ديكران & \\
\hline & & & & & & & $1 / r \Delta \Lambda$ &.$/ \cdots 1$ & II/Frs &.$/ 419$ & PTGI_18 & & \\
\hline & & & & & & & $|/ F Y|$ & $\cdot / \cdots 1$ & $|1 / 4| 0$ &.$/ s p F$ & PTGI_20 & & \\
\hline
\end{tabular}




\begin{tabular}{|c|c|c|c|c|c|c|c|c|c|c|c|c|c|}
\hline \multicolumn{2}{|c|}{ آمار توصيفى } & \multicolumn{9}{|c|}{ تحليل عاملى تأييدى } & \multirow[b]{2}{*}{ شاخص } & \multirow{2}{*}{ زير (متغيرهاى } & \multirow[b]{2}{*}{ مقياس } \\
\hline انحراف & ميانغين & متقاطع روايى & ميانكين واريانس & تر يايايى & شاخص & كرونباخ & واريانس & معنادارى & آماره تى & بارعاملى & & & \\
\hline \multirow{5}{*}{$r / . r$} & \multirow{5}{*}{$\mid r / \wedge s$} & \multirow{5}{*}{$\cdot / \mu F$} & \multirow{5}{*}{. /OFq } & \multirow{5}{*}{$\cdot / 1 \Delta S$} & \multirow{5}{*}{$\cdot / 119$} & \multirow{5}{*}{$\cdot / \vee \wedge 9$} & $1 / 9 V Y$ &.$/ \cdots 1$ & rl/AVr & $\cdot / V \vee \Delta$ & RISC_01 & \multirow{5}{*}{ تذيرش مثبت } & \\
\hline & & & & & & & $1 / 190$ &.$/ \cdots 1$ & $\Lambda / r \& \Lambda$ &.$/ 011$ & RISC_02 & & \\
\hline & & & & & & & l/ArF &.$/ \cdot 1$ & $r F / I V V$ & $\cdot / 1 / V$ & RISC_04 & & \\
\hline & & & & & & & l/AFF & $\cdot / . .1$ & 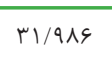 & ./Arr & RISC_05 & & \\
\hline & & & & & & & $1 / \uparrow \& \Lambda$ &.$/ . .1$ & $\mid V / \cdot 1 r$ & $\cdot / V r$ & RISC_08 & & \\
\hline \multirow{6}{*}{$\Delta / \&$} & \multirow{6}{*}{$19 / 9 V$} & \multirow{6}{*}{$\cdot / r \vee \Delta$} & \multirow{6}{*}{$\cdot / \Delta \Delta \Delta$} & \multirow{6}{*}{ - /AMr } & \multirow{6}{*}{ - /AFD } & \multirow{6}{*}{$\cdot / \wedge \mu \wedge$} & $1 / 4 \cdot r$ &.$/ .1$ & $10 / 1.9$ & $\cdot / V \cdot G$ & RISC_06 & \multirow{6}{*}{ تمنفى و تحمل اثرات . } & \\
\hline & & & & & & & $|/ G \mu|$ &.$/ . .1$ & 19/Afq & $\cdot / V r \Delta$ & RISC_07 & & \\
\hline & & & & & & & $r / 1 \wedge \varphi$ &.$/ \cdots 1$ & $r F / v \Delta r$ & ./Ars & RISC_14 & & \\
\hline & & & & & & & $1 / 0 \cdot 0$ & $\cdot / \cdot 1$ & $11 / 1 \cdot r$ & / / $9 \Delta \mu$ & RISC_15 & & \\
\hline & & & & & & & I/VYA & $\cdot / \cdot 1$ & $\mid N / F \& V$ & $\cdot / V \Delta q$ & RISC_18 & & \\
\hline & & & & & & & $1 / 917$ &.$/ .1$ & $r V / / r r$ & $\cdot / \mathrm{V}$ & RISC_19 & & \\
\hline \multirow{2}{*}{$1 / 94$} & \multirow{2}{*}{$s / \Delta \Lambda$} &.$/ 101$ & .1991 & . $(1) \&$ & . VYGA &.$/ V O V$ & $1 / 1 \wedge V$ &.$/ \cdots 1$ & Ir/rrr & $\cdot /$ VOr & RISC_03 & تأثش ات معنهـ & تاب آوري \\
\hline & &.$/ 101$ & $\cdot \mid 741$ & ·/A17 & - /VyT & - /rar & I/IAV &.$/ .1$ & $r V / \Delta \cdot \Lambda$ & $\cdot / 9 \cdot r$ & RISC_09 & نيرات معوك & \\
\hline & & & & & & & $1 / v \cdot r$ & $\cdot / \cdot 1$ & $\mid q / \varepsilon r$ &.$/ S V F$ & RISC_10 & & \\
\hline & & & & & & & $r / 199$ &.$/ . .1$ & $r \cdot / r r \Delta$ & $\cdot / 1 \cdot \Delta$ & RISC_11 & & \\
\hline & & & & & & & $1 / \wedge 90$ &.$/ \cdot 1$ & |N/9V4 & $\cdot / V \Delta A$ & RISC_12 & & \\
\hline & & & & & & & $r / \backslash \Lambda \Lambda$ & $\cdot / . \cdot 1$ & $r \mu / 1$ & . /VAr & RISC_16 & صلاحيت و & \\
\hline $4 / 99$ & $r \mid / \Delta 1$ & $\cdot / \& T V$ & $\cdot / 09$ & $\cdot / 91$ & $\cdot / 191$ & $\cdot / \wedge \wedge \vee$ & $r / .99$ &.$/ .1$ & $19 / \wedge 99$ & . JYAr & RISC_17 & كفايت فردى & \\
\hline & & & & & & & $1 / 90$ &.$/ . \cdot 1$ & IV/rT &.$/ 210$ & RISC_23 & & \\
\hline & & & & & & & $r / \cdot G$ & $\cdot / \cdot 1$ & rI/rrr & $\cdot / V V r$ & RISC_24 & & \\
\hline & & & & & & & $1 / V V F$ &.$/ .1$ & $\mid r / V \Delta \Lambda$ & $\cdot / V \cdot \Delta$ & RISC_25 & & \\
\hline & & & & & & & $1 /$ /q1 &.$/ \ldots 1$ & $10 / V \cdot V$ & . JPF & RISC_13 & & \\
\hline$r / 9 V$ & N/Dr & $\cdot / \mu F q$ &.$/ 9 V \mu$ & $\cdot / \Lambda 9$ & ./VVS & $\cdot / V D S$ & $1 / 091$ &.$/ \cdots 1$ & rN/TYF & ./Ar| & RISC_21 & خود كنترلى & \\
\hline & & & & & & & $1 / \wedge \mid f$ &.$/ . .1$ & $\Delta r / \& q$ & $\cdot / 1 \wedge 1$ & RISC_22 & & \\
\hline & & & & & & & $r / 11$ &.$/ .1$ & rr/frs & $\cdot|\wedge \mu|$ & MPSS_01 & & \\
\hline $0 / \varphi^{\prime}$ & & & & & & & $r / r q \vee$ &.$/ .1$ & $r F / r \Delta \Lambda$ & $\cdot / \wedge \subseteq \wedge$ & MPSS_02 & اف اد مهم ديخ & \\
\hline $0 / 7 q$ & $r T / 10$ & $\cdot / 011$ & $\cdot / V^{\mu}$ &.$/ 910$ & ·/AマA & ·/AVS & $r / F \cdot r$ &.$/ .1$ & $r V / \& 91$ & $\cdot / \Lambda g F$ & MPSS_05 & اقر اد مهرم ديد & \\
\hline & & & & & & & r/rGY &.$/ . .1$ & $r N / \Lambda \cdot F$ & $\cdot / \Lambda \Delta F$ & MPSS_10 & & \\
\hline & & & & & & & $r / \Delta 10$ & $\cdot / \cdot 1$ & $F 0 / 19$ & $\cdot / 9 \cdot r$ & MPSS_03 & & \\
\hline $0 / .1$ & $r \mu / q \Delta$ & $\cdot / 4 \cdot F$ & . / १q &.$/ q 4 q$ &.$/ 94$ &.$/ 914$ & T/KTS &.$/ \cdot 1$ & $\Delta F / \cdot V q$ &.$/ 940$ & MPSS_04 & خانيادر خادر & حمايت \\
\hline W/. & 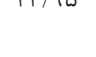 & .78 .1 & 年 & . & . & & $r / 190$ &.$/ .1$ & $r \cdot / \cdot r$ & $\cdot / 1999$ & MPSS_08 & كانوادة. & اجتماعى \\
\hline & & & & & & & r/TAF &.$/ . .1$ & IN/Tr & ./Ars & MPSS_11 & & \\
\hline & & & & & & & r/rqr & $\cdot / \cdot .1$ & $\Delta N / צ \hookrightarrow Y$ &.$/ 9.9$ & MPSS_06 & & \\
\hline$\varepsilon / \mu_{1}$ & & & & & & & $r / r G \Lambda$ &.$/ .1$ & DI/rGK &.$/ 911$ & MPSS_07 & $\therefore$ & \\
\hline S/rA & $r \cdot / 90$ & $\cdot / 41$ & $\cdot / \vee 9 \wedge$ & $\cdot / 9 P^{\circ}$ & ./9イ^ &.$/ 910$ & $r / \Delta 1$ & $\cdot / \cdot .1$ & $90 / 194$ &.$/ 9 r v$ & MPSS_09 & دوستان & \\
\hline & & & & & & & $r / 191$ & $\cdot / \cdot .1$ & IN/HFG & $\cdot / \Lambda 11$ & MPSS_12 & & \\
\hline
\end{tabular}


ضر ايب همبستكى بررسى رابطهى ميان متغيرهاى ينهان را به هر متغير مكنون بايد براى شاخصهاى مربوط به خودش بيشتر از

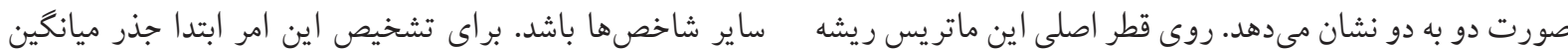

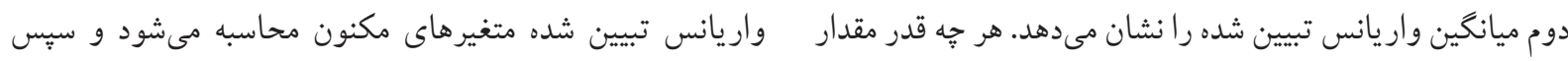

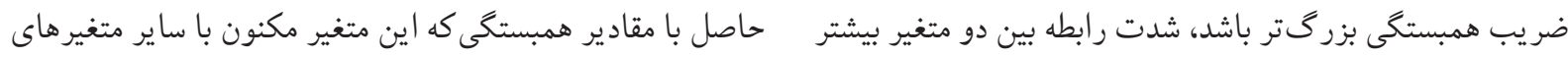

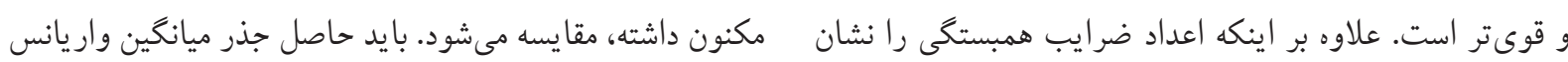

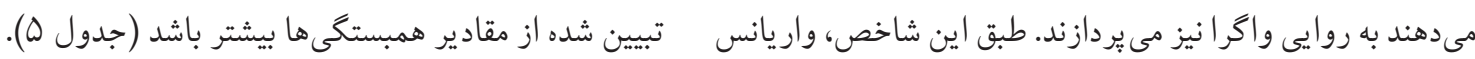
جدول ه. ضرايب همبستخى يِير سون و شاخص اعتبار واكرا

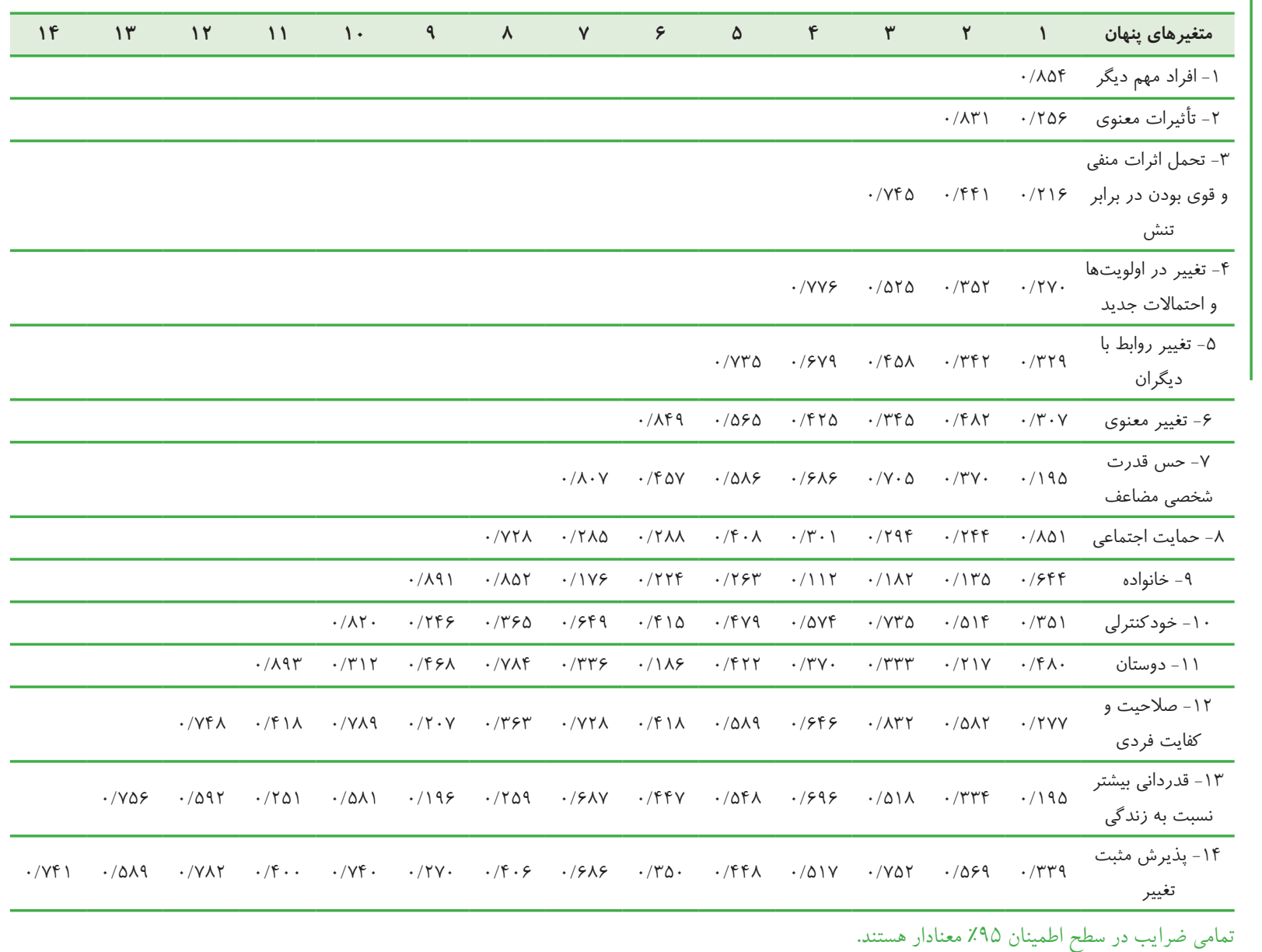

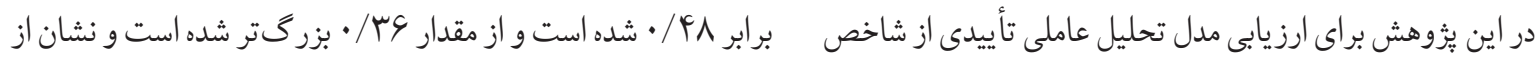

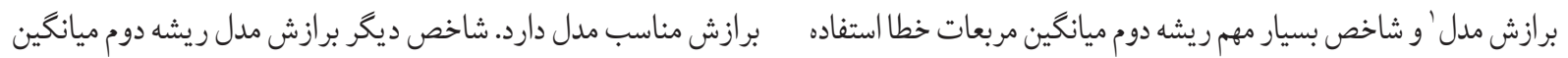

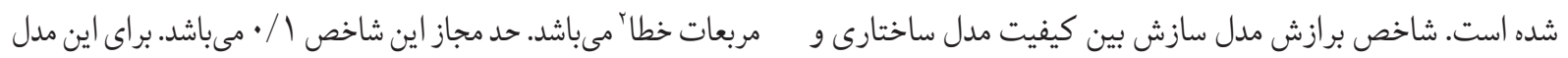

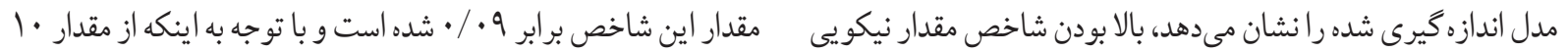
برازش از وب/ • برازش مدل را نشان مىدهد. مقدار شاخص برازش درصد كمتر مىباشدو مىتوان كفت مدل برازش مناسبى داشته است. 


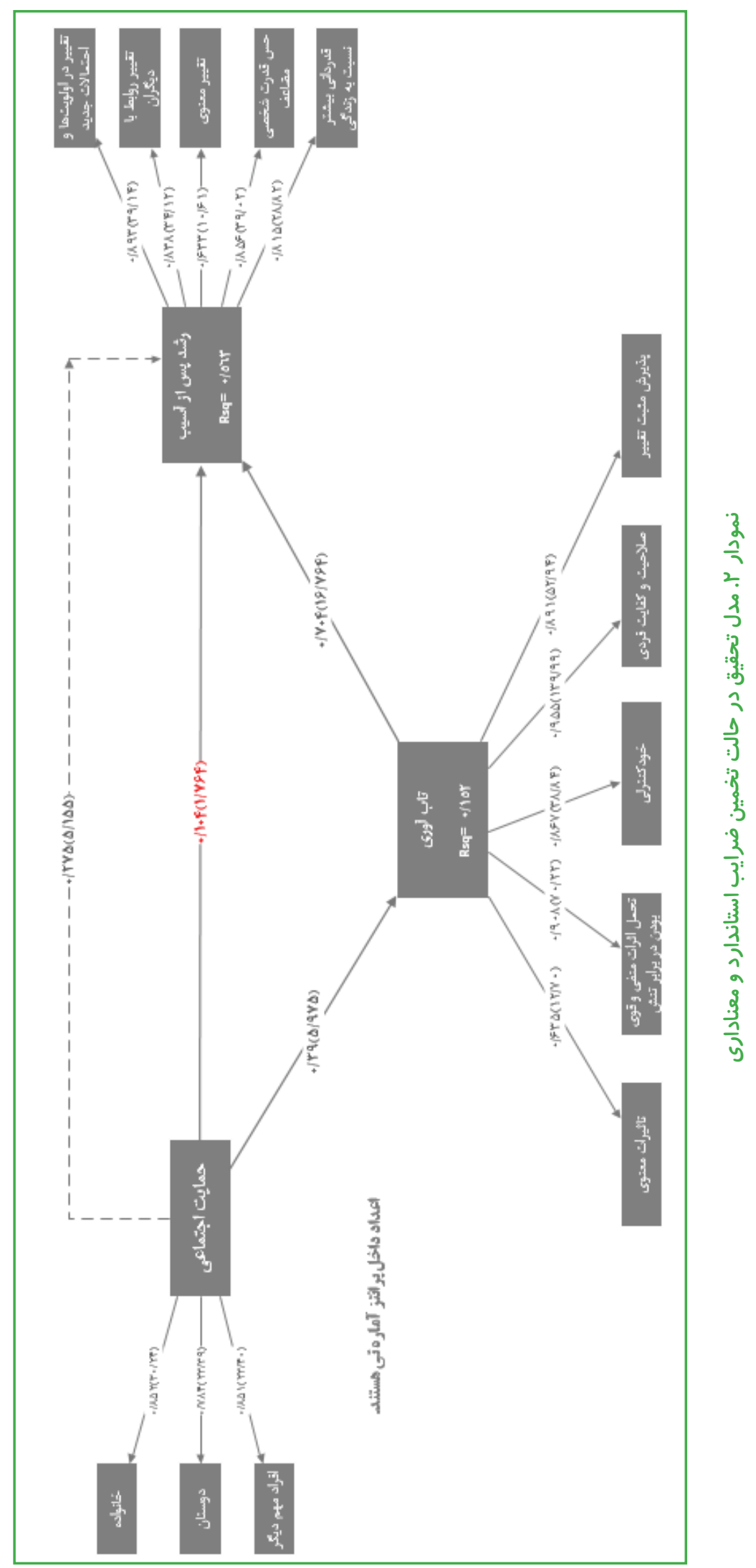


تحقيق نيز معادلات ساختارى هستند. تأثير حمايت اجتماعى بر تاب آورى داراى مقدار معنادارى معادي

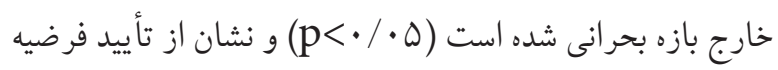

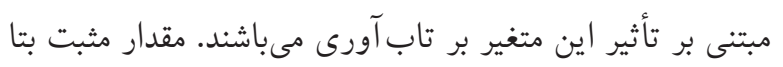

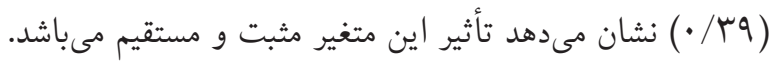

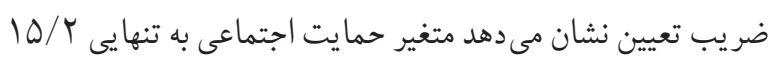
درصد از تغييرات تاب آورى را توضيح داده است (جدول و).
نمودار Y مدل معادلات ساختارى را در حالت تخمين ضرايب

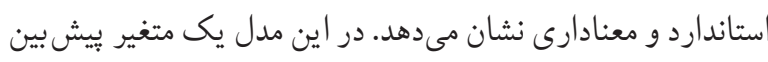

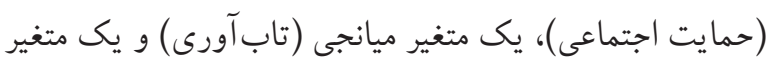

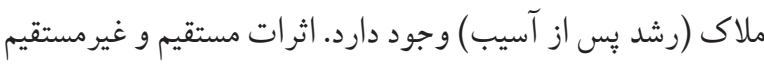

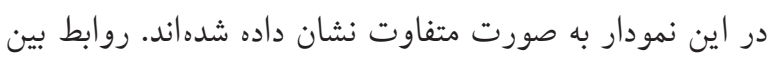

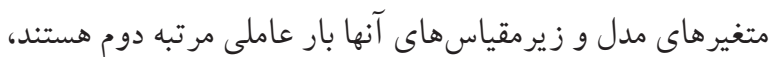

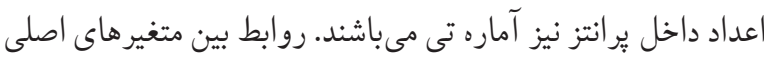

جدول צ. نتايج مدل معادلات ساختارى و آزمون سوبل فرضيههاى تحقيق

\begin{tabular}{|c|c|c|c|c|c|}
\hline \multicolumn{6}{|c|}{ نتايج معادلات ساختارى } \\
\hline جهت & وضعيت فرضيه & سطح معنادارى & آماره تى & بتا & فرضيات تحقيق \\
\hline رابطه مثبت & ت ت ت أييد &.$/ \cdot 1$ & $\Delta / 9 \vee \Delta$ & $\cdot / \mu q$ & حمايت اجتماعى ٪ تاب آورى \\
\hline رابطه مثبت & تأييد &.$/ \cdot 1$ & $19 / V G 4$ & $\cdot / \mathrm{V} \cdot \mathrm{F}$ & تاب آورى ٪ رشد يس از آسيب \\
\hline & & $\cdot / \cdot \vee \wedge$ & I/VGF & $\cdot / 1 \cdot F$ & حمايت اجتماعى ٪ رشد يس از آسيب \\
\hline \multicolumn{6}{|c|}{ نتايج آزمون سوبل } \\
\hline جهت & وضعيت فرضيه & سطح معنادارى & آماره سوبل & بتا & فرضيه مبتنى بر ميانجى \\
\hline رابطه مثبت & تأييد & $\cdot 1 \cdot \cdot 1$ & $\Delta / 10 \Delta$ & $\cdot / r \vee \Delta$ & 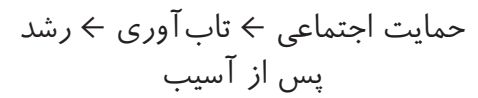 \\
\hline
\end{tabular}

SRMR=0/09, GOF=0/480

$|t|>1.96$ Significant at $\mathrm{P}<0.05,|t|>2.58$ Significant at $\mathrm{P}<0.01$

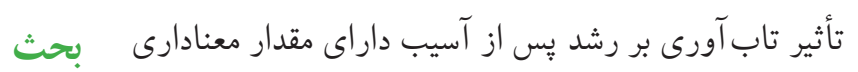

در زمينه رشد بِ از آسيب و حمايت اجتماعى ادراك شده، مطالعات

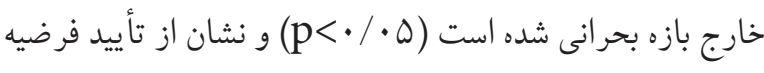

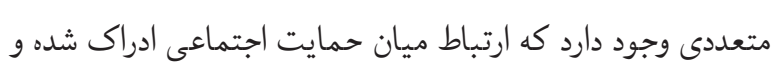

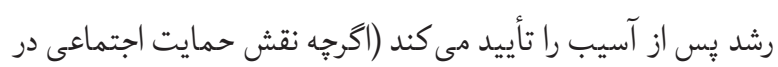

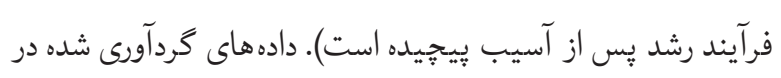

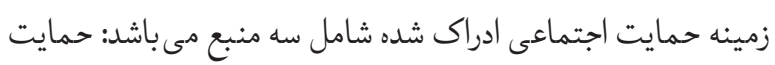

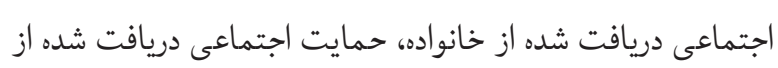
دوستان و حمايت اجتماعى دريافت شده قابل توجه از افراد مهم.

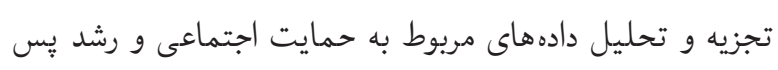
از آسيب تأييدكننده ارتباط ميان حمايت اجتماعى و رشد ورديل آسيب هستند. هـم جنين تحقيقات نشان مى دهند كه منبع حمايت

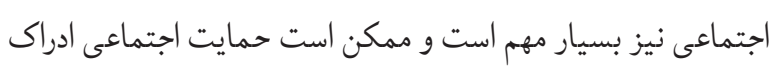
شده از خانواده، متغيرهاى ديخر را تحت تأثير قرار دهند. مبتنى بر تأثير اين متغير بر رشد بِ بـ از آسيب مى باشند. مقدار مثبت

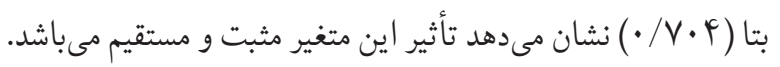

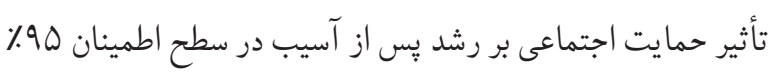

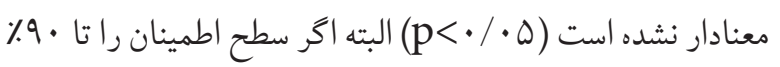

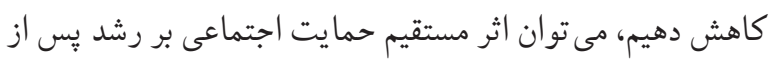

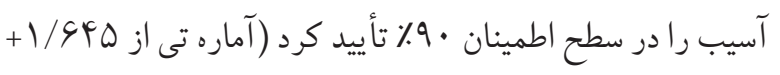

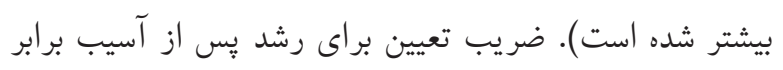

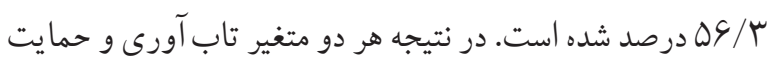

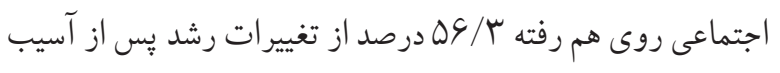

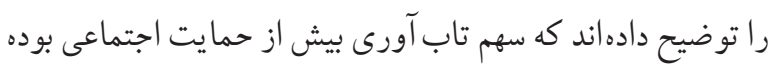

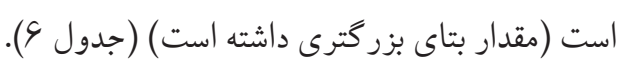


تأثير كذار در رشد پِ از آسيب حمايت اجتماعى مى باشد (Y人). زانگ و ورهوف 9 (Y9)، نشان دادند حمايت خانوادكى بيمار،

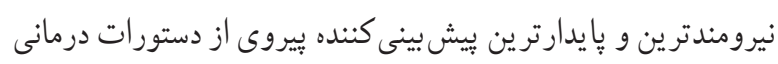

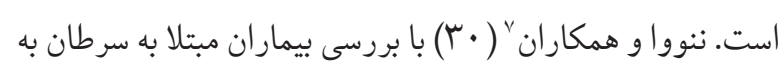

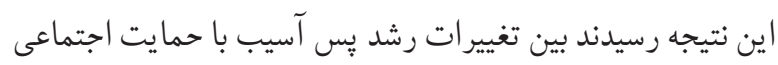
و حوزههاى مختلف آن رابطه معنادار وجود دارد.

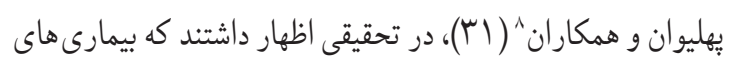

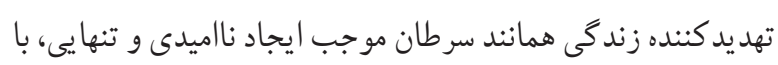

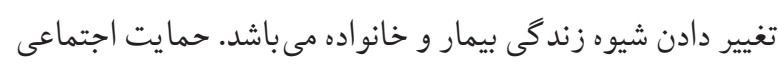

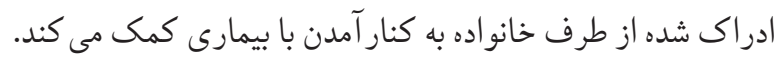
اين محققيق هم جنين رابطه مثبتى ميان ناميدى و تنهايى و رابطه

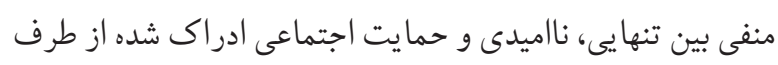

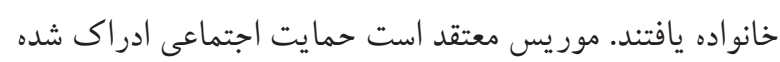
از سوى خانو اده به كنار آمدن با بيمارى كمى مى كند. حمايت اجتماعى ادراك شده و باورهاى مذهبى در بيماران مبتلا به سرطان با تغييرات مثبت يس از آسيب، رابطه مستقيم

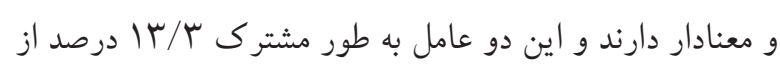

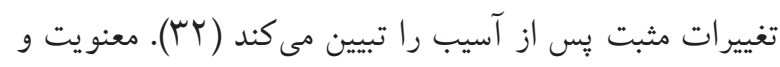

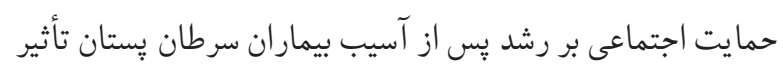

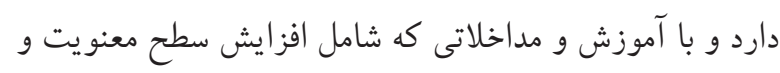
حمايت اجتماعى گردد، مى توان ميزان رشد بِ إن از آسيب بيماران

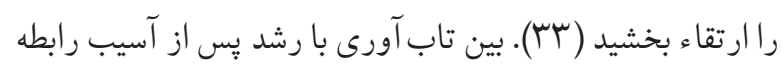

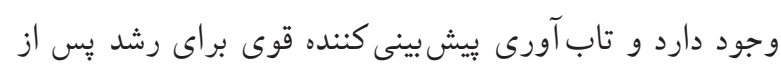

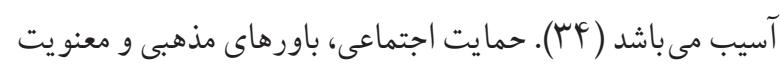

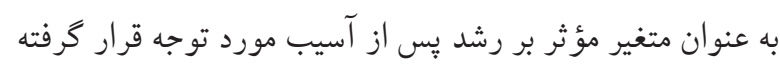
است (ه广). خوشبينى، حمايت اجتماعى، معنويت، كنار آمدن از

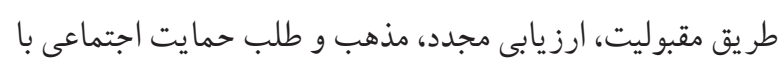

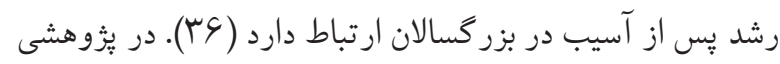

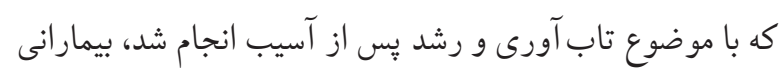

6. Zhang \& Verhoef

7. Nenova et al

8. Pehlivan et al
هر جه فرد مورد حمايت اجتماعى بيشترى از جانب اطر افيان

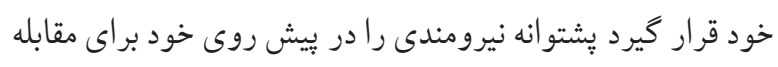
با بيمارى دريافت مى كند. در نتيجه، با وجود تهديد كننده بودن

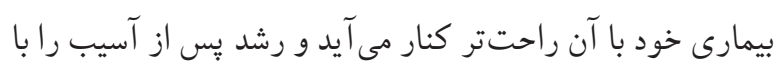
احتمال بيشترى تجربه مى كند. حمايت خانو اده به عنوان يكى از از

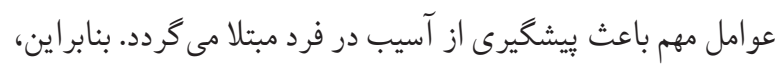

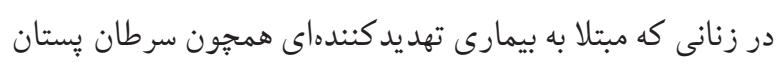
شدهاند، احساس دريافت حمايت اجتماعى از سوى اطرافيان از

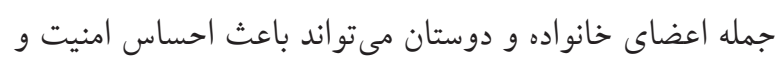

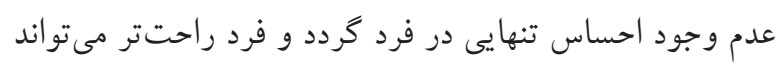
روى كمك ديكران، حساب باز كند و در مورد هيجانات خود

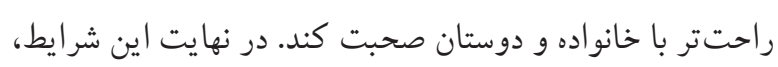

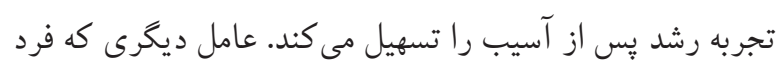

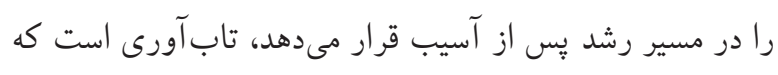

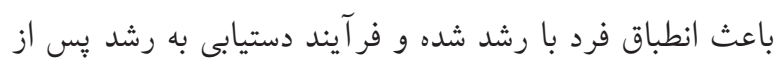
آسيب را فراهم مى كند.

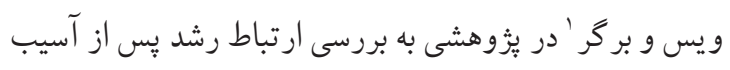

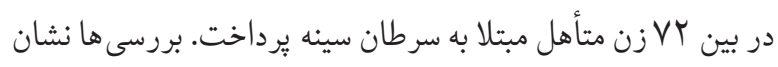
داد زنانى كه حمايت بيشترى از سوى همسران شان دريافت كرده

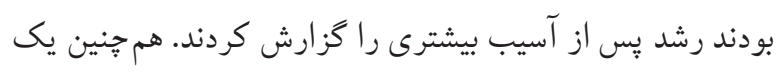

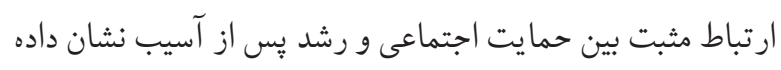

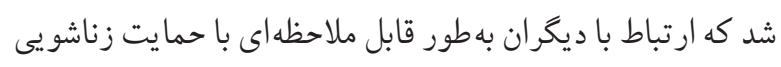

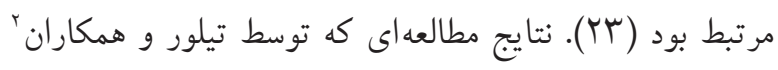

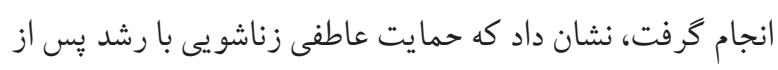

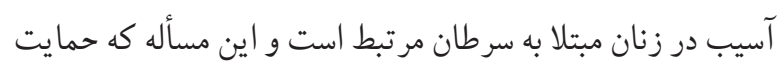
عاطفى خانواده از والدين داغديده با رشد پِ از از آسيب مرتبط

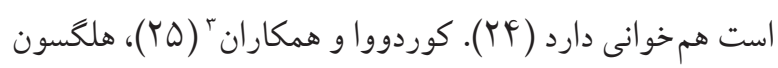

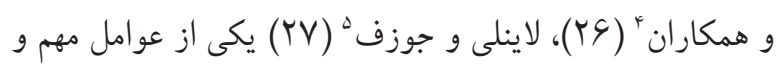

1. Weiss \& Berger

2. Taylor et al

3. Cordova et al

4. Helgeson et al

5. Linley \& Joseph 
مثبت و معنادارى دارد.

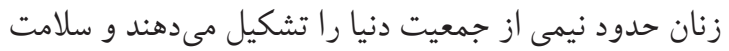
آنان از اهميت خاصى برخوردار است. با توجه به شيوع سرطان

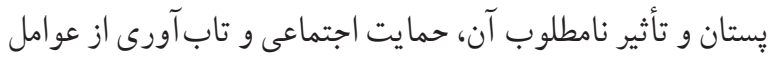

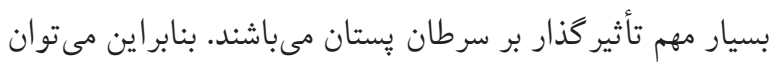

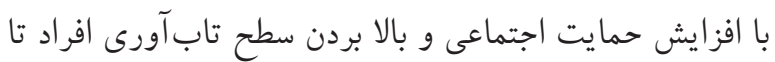

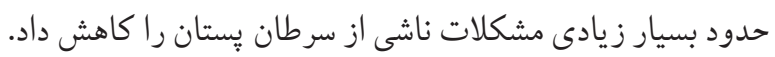

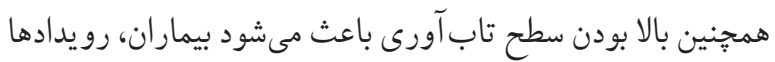

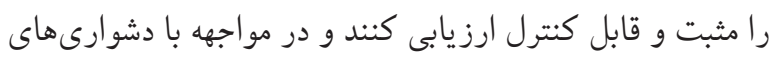
مرتبط با بيمارى دجار آشفتكى كمترى شوند. در نتيجه مى توان

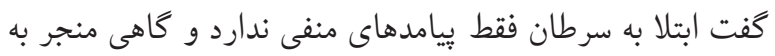

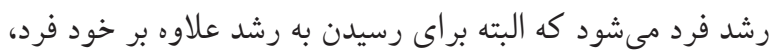
نزديكان و اطر افيان نيز مى توانند تأثير كذار باشند.

$$
\text { تشكر و قدردانى }
$$
اين مقاله بركرفته از پاياننامه دكترى روانشناسى سلامت مصوب شده در دانشعاه آزاد اسلامى واحد امارات متحده عربى با كد اخلاق مهاق امى باشد. نويسندگان از تمامى R.SBMU.RETECH.1399.377 كسانى كه ما را در انجام اين يُزوهش يارى نمودند تشكر و قدردانى

مى نمايند.

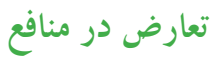
نويسندگان اظهار مىدارند هيج گونه تعارض منافعى در مورد اين

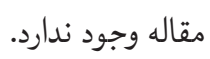

كه رشد بِ از آسيب بالاترى را گزارش كردهاند از تاب آورى

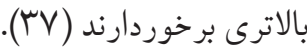

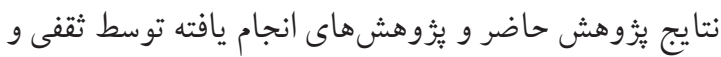

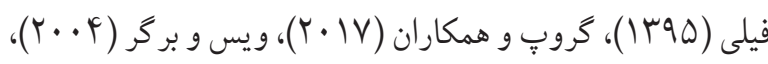

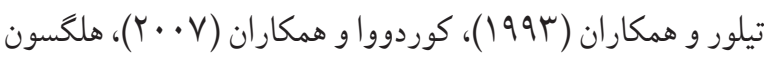

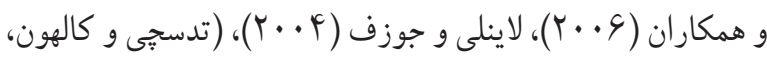

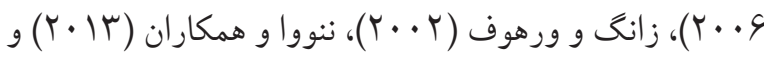

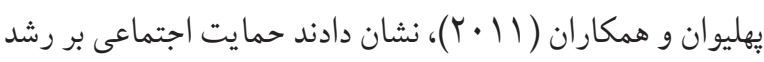
يس از آسيب، تأثير مثبت و معنادارى دارد. نتايج يزوهش حاض حاض با ساير يزوهش ها همسو مى بـاشد.

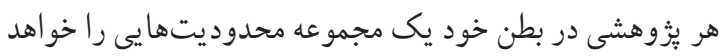

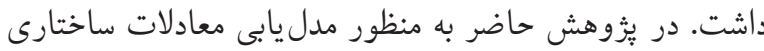

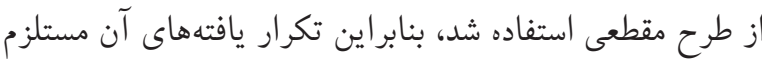
بكار گيرى طرح هاى طولى است. هم جنين استفاده از ابزارهاى ديخر

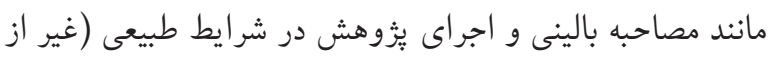

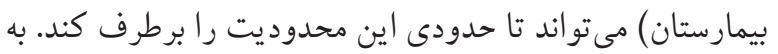
طور كلى در ارتباط با دستاوردهاى اين يُزوهش مى توان بيان كرد

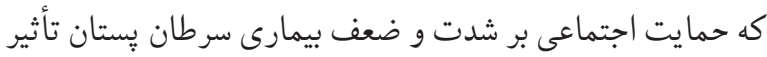

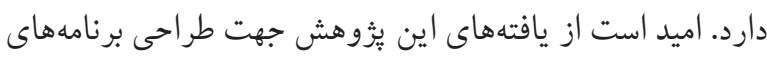
ييشخير انه و انجام يُوهشهاى گستردهتر در حوزه سرطان بستان

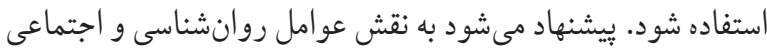
و نحوه تأثير آنها بر بيمارىهاى جسمى مانند بيمارى سرطان يستان در فعاليتهاى يُّوهشى و بالينى اهميت بيشترى داده شود.

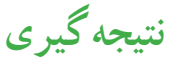
نتايج يزوهش حاضر نشان داد بين حمايت اجتماعى ادراك شده و

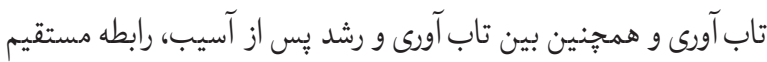

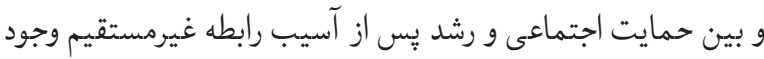

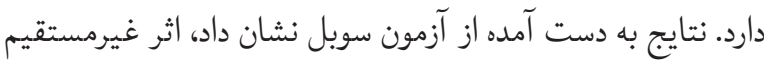
حمايت اجتماعى بر رشد پِ از آسيب به واسطه تاب آورى در درد

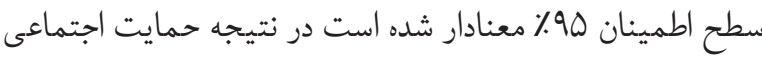
بر رشد پِ از آسيب با توجه به نقش ميانجى تابآورى تأثير 


\section{References}

1. Jassim GA, Whitford DL. Understanding the experiences and quality of life issues of Bahraini women with breast cancer. Social science \& medicine. 2014;107:189-95. https://doi.org/10.1016/j.socscimed.2014.01.031

2. Zeichner RL, Kibler JL, Zeichner SB. Relationship between mindfulness-based stress reduction and immune function in cancer and HIV/AIDS. Cancer and Clinical Oncology. 2013;2(1):62. https://doi.org/10.5539/cco.v2n1p62

3. Pedram M, Mohammadi M, Naziri G, Aeinparast N. Effectiveness of cognitive-behavioral group therapy on the treatment of anxiety and depression disorders and on raising hope in women with breast cancer. Quarterly Journal of Women and Society. 2010;1(4):34-61.

4. Bagheri moghimi behbadi M, Mazaheri M. Study Of Coping Styles and Self-efficacy In Women With Breast Cancer For Women in the General. Journal of Health Literacy. 2019;4(3):66-76..

5. Hashemi Z, Afshari A, Einy S. The effectiveness of acceptance and commitment education on improving the mental health and quality of life of elderly people with cancer. Iranian Journal of Health Education and Health Promotion. 2020;8(2):160-71. https://doi.org/10.29252/ijhehp.8.2.160

6. Tedeschi R G, Calhoun L G. Trauma \& Transformation: Growing in the Aftermath of Suffering; Thousand Oaks 1995: Sage Publications. https://doi.org/10.4135/9781483326931

7. Frankl VE. Logotherapy and the challenge of suffering. Pastoral Psychology. 1962;13(5):25-8. https://doi.org/10.1007/BF01762985

8. Schroevers MJ, Helgeson VS, Sanderman R, Ranchor AV. Type of social support matters for prediction of posttraumatic growth among cancer survivors. Psycho-Oncology. 2010;19(1):46-53. https://doi.org/10.1002/pon.1501

9. Tedeschi RG, Calhoun LG. The Posttraumatic Growth Inventory: Measuring the positive legacy of trauma. Journal of traumatic stress. 1996;9(3):455-71. https://doi.org/10.1002/jts.2490090305

10. Ozkan S, Ogce F. Importance of social support for functional status in breast cancer patients. APJCP 2008; 9(4): 601-4.

11. Ghoreishi M-S, Vahedian-Shahroodi $M$, Jafari $A$, Tehranid $H$. Self-care behaviors in patients with type 2 diabetes: Education intervention base on social cognitive theory. Diabetes \& Metabolic Syndrome: Clinical Research \& Reviews. 2019;13(3):2049-56. https://doi.org/10.1016/j.dsx.2019.04.045

12. Arabzadeh Baniasadi R, Rahmati A. Perceived Social Support From Family As a Mediator Between Personality
Dimensions and Psychological Well-Being Among School Counseorsl. QJFR 2015; 12 (3): 33-50.

13. Ghobari Bonab B, Rafiekhah M, Mohajerani M. Relations of Attachment to God and Perceived Social Support with Post Traumatic Growth in Mothers of Children with Physical Disabilities. Journal of Psychological Achievements. 2014;21(1):1-14.

14. West W. Psychotherapy \& spirituality: crossing the line between therapy and religion. 2000; New York, NY: SAGE Publications.

15. Underwood LG, Teresi JA. The daily spiritual experience scale: Development, theoretical description, reliability, exploratory factor analysis, and preliminary construct validity using health-related data. Annals of Behavioral Medicine. 2002;24(1):22-33. https://doi.org/10.1207/S15324796ABM2401_04

16. Meyers LS, Gamst G, Guarino A. Applied Multivariate Research: Design and Interpretation: SAGE; 2006.

17. Heidarzadeh $M$, Rassouli M, Shahbolaghi F, Alavi Majd H, Mirzaei H, Tahmasebi M. Assessing dimensions of posttraumatic growth of cancer in survived patients. Journal of Holistic Nursing And Midwifery. 2015;25(2):3341.

18. Zimet GD, Dahlem NW, Zimet SG, Farley GK. The multidimensional scale of perceived social support. Journal of personality assessment. 1988;52(1):30-41. https://doi.org/10.1207/s15327752jpa5201_2

19. Cheraghi M, DavariDolatabadi E. Development and psychometric evaluation of the heart failure patients' perceived social support inventory. Journal of Rafsanjan University of Medical Sciences. 2016;15(3):195-208.

20. Zimet GD, Powell SS, Farley GK, Werkman S, Berkoff KA. Psychometric characteristics of the multidimensional scale of perceived social support. Journal of personality assessment. 1990;55(3-4):610-7. https://doi.org/10.1080/00223891.1990.9674095

21. Connor KM, Davidson JR. Development of a new resilience scale: The Connor-Davidson resilience scale (CD-RISC). Depression and anxiety. 2003;18(2):76-82. https://doi.org/10.1002/da.10113

22. Ahangarzadeh Rezaei S, Rasoli M. Psychometric Properties of The PERSIAN Version of "Conner-Davidson Resilience Scale" In Adolescents With Cancer. J Nurs Midwifery. 2015; 13 (9):739-747.

23. Weiss T, Berger R. Reliability and validity of a Spanish version of the Posttraumatic Growth Inventory. Research on social work practice. 2006;16(2):191-9. https://doi.org/10.1177/1049731505281374

24. Taylor SE, Aspinwall LG, Giuliano TA, Dakof GA, Reardon KK. Storytelling and Coping With Stressful Events 1. 
Journal of Applied Social Psychology. 1993;23(9):703-33. https://doi.org/10.1111/j.1559-1816.1993.tb01111.x

25. Cordova MJ, Giese-Davis J, Golant M, Kronenwetter C, Chang V, Spiegel D. Breast cancer as trauma: Posttraumatic stress and posttraumatic growth. Journal of Clinical Psychology in Medical Settings. 2007;14(4):308-19. https://doi.org/10.1007/s10880-007-9083-6

26. Helgeson VS, Reynolds KA, Tomich PL. A meta-analytic review of benefit finding and growth. Journal of consulting and clinical psychology. 2006;74(5):797. https://doi.org/10.1037/0022-006X.74.5.797

27. Linley PA, Joseph S. Positive change following trauma and adversity: A review. Journal of traumatic stress: official publication of the international society for traumatic stress studies. 2004;17(1):11-21. https://doi.org/10.1023/B:JOTS.0000014671.27856.7e

28. Tedeschi RG, Calhoun LG. " Posttraumatic growth: Conceptual foundations and empirical evidence". Psychological inquiry. 2004;15(1):1-18. https://doi.org/10.1207/s15327965pli1501_01

29. hang J, Verhoef MJ. Illness management strategies among Chinese immigrants living with arthritis. Social science \& medicine. 2002;55(10):1795-802. https://doi.org/10.1016/S0277-9536(01)00311-2

30. Nenova M, DuHamel K, Zemon V, Rini C, Redd WH. Posttraumatic growth, social support, and social constraint in hematopoietic stem cell transplant survivors. Psycho-oncology. 2013;22(1):195-202. https://doi.org/10.1002/pon.2073

31. Pehlivan S, Ovayolu O, Ovayolu N, Sevinc A, Camci C. Relationship between hopelessness, loneliness, and perceived social support from family in Turkish patients with cancer. Supportive Care in Cancer. 2012;20(4):733-9. https://doi.org/10.1007/s00520-011-1137-5

32. Kashani FL, Shamkoeyan L, Esmaeil M, Vaziri S. The relations of perceived social support and religious beliefs with the post traumatic growth in cancer patients. Developmental psychology: Iranian psychologists. 2014;10(39):285-95.

33. Nikmanesh Z. Prediction of posttraumatic growth base on of spirituality and social support in patients with breast cancer. Iranian Quarterly Journal of Breast Disease. 2013;6(2):35-42.

34. Dong X, Li G, Liu C, Kong L, Fang $Y$, Kang X, et al. The mediating role of resilience in the relationship between social support and posttraumatic growth among colorectal cancer survivors with permanent intestinal ostomies: A structural equation model analysis. European Journal of Oncology Nursing. 2017;29:47-52. https://doi.org/10.1016/j.ejon.2017.04.007

35. Yeung NC, Lu Q. Perceived stress as a mediator between social support and posttraumatic growth among Chinese American breast cancer survivors. Cancer nursing. 2018;41(1):53-61. https://doi.org/10.1097/NCC.0000000000000422

36. Meyerson DA, Grant KE, Carter JS, Kilmer RP. Posttraumatic growth among children and adolescents: A systematic review. Clinical psychology review. 2011;31(6):949-64. https://doi.org/10.1016/j.cpr.2011.06.003

37. Greup SR, Kaal SE, Jansen R, Manten-Horst E, Thong MS, van der Graaf WT, et al. Post-traumatic growth and resilience in adolescent and young adult cancer patients: An overview. Journal of adolescent and young adult oncology. 2018;7(1):1-14. https://doi.org/10.1089/jayao.2017.0040 